\title{
Multi-Directional Seismic Assessment of Historical Masonry Buildings by Means of Macro-Element Modelling: Application to a Building Damaged during the L'Aquila Earthquake (Italy)
}

\author{
Francesco Cannizzaro ${ }^{1, *}$ (D), Bartolomeo Pantò ${ }^{1}$, Marco Lepidi ${ }^{2}$, Salvatore Caddemi ${ }^{1}$ \\ and Ivo Caliò ${ }^{1}$ \\ 1 Department of Civil Engineering and Architecture, University of Catania, 95125 Catania, Italy; \\ bpanto@dica.unict.it (B.P.); scaddemi@dica.unict.it (S.C.); icalio@dica.unict.it (I.C.) \\ 2 Department of Civil Chemical and Environmental Engineering, University of Genoa, 16145 Genoa, Italy; \\ marco.lepidi@unige.it \\ * Correspondence: francesco.cannizzaro@dica.unict.it; Tel.: +39-095-738-2275
}

Received: 11 September 2017; Accepted: 6 November 2017; Published: 13 November 2017

\begin{abstract}
The experience of the recent earthquakes in Italy caused a shocking impact in terms of loss of human life and damage in buildings. In particular, when it comes to ancient constructions, their cultural and historical value overlaps with the economic and social one. Among the historical structures, churches have been the object of several studies which identified the main characteristics of the seismic response and the most probable collapse mechanisms. More rarely, academic studies have been devoted to ancient palaces, since they often exhibit irregular and complicated arrangement of the resisting elements, which makes their response very difficult to predict. In this paper, a palace located in L'Aquila, severely damaged by the seismic event of 2009 is the object of an accurate study. A historical reconstruction of the past strengthening interventions as well as a detailed geometric relief is performed to implement detailed numerical models of the structure. Both global and local models are considered and static nonlinear analyses are performed considering the influence of the input direction on the seismic vulnerability of the building. The damage pattern predicted by the numerical models is compared with that observed after the earthquake. The seismic vulnerability assessments are performed in terms of ultimate peak ground acceleration (PGA) using capacity curves and the Italian code spectrum. The results are compared in terms of ultimate ductility demand evaluated performing nonlinear dynamic analyses considering the actual registered seismic input of L'Aquila earthquake.
\end{abstract}

Keywords: macro-model approach; monumental masonry structures; L'Aquila earthquake; historical structural analyses; seismic assessment; cultural heritage protection; irregular structures; 3DMacro software; HiStrA software

\section{Introduction}

In the last ten years, three destructive earthquakes struck Italy causing severe damage to the cultural heritage of the country. The experiences of L'Aquila (2009), Emilia (2012) and, more recently, Amatrice (2016) demonstrated the vulnerability of the buildings to possible seismic events. In particular, historical constructions cannot be considered as modern structures, since their preservation is crucial to maintain the tourism potential of many sites and to preserve the conservation of the historical memories of communities.

The mentioned seismic events gave a strong impulse towards the understanding and the interpretation of the seismic response of structures with reference to different structural typologies [1-3], 
especially if exposed to high seismic hazards or unfavourable soil properties [4]. In particular, a large effort was devoted to the analysis of masonry monumental structures, such as churches [5-9]. However, more rarely, studies were devoted to historical palaces [10-17], which are characterized by a wider spectrum of different typologies and peculiarities, and the large part of these studies is based on the observation on the field of the effects of the earthquakes without a complete numerical counterpart.

With respect to churches, which usually kept the original configuration during the centuries, ancient palaces are often characterized by structural changes made during their life mainly due to functional needs. The latter aspect implies a more difficult interpretation and prediction of the structural response. A further difference with respect to churches and other ancient structures [17] is related to the out-of-plane behaviour of the walls, which usually involves a large part of the building in the case of churches, whereas it is often a local collapse mechanism in the case of palaces.

In this paper, the case of Palazzo Gualtieri is investigated. The building was the object of a preliminary study [18] in the immediate aftermath of the main shock within a larger campaign of investigation of several buildings of the city of L'Aquila. In this paper, a historical and architectural description of the building is provided and a survey of the past strengthening interventions is reported to facilitate the understanding of the main structural features of the building.

Then, taking advantage of some numerical models previously proposed by the authors, a deep numerical investigation on the building was performed. In particular, the adoption of a numerical simplified model proposed for unreinforced masonry structures (URM) [19] and in-filled frame structures (IFS) [20-22], which was implemented in a dedicated software environment allowed implementing a global numerical model of the building on which nonlinear static analyses were performed considering the influence of the direction of the input. Such an approach was also compared in the literature with other numerical strategies on definite structural typologies, such as URM buildings [23] and slender towers [24], showing its reliability with reference to different buildings typologies and it also appeared suitable in the case of ancient masonry palaces. In the numerical applications reported here, the interaction between the in-plane and out-of-plane responses is not considered in the simulations, thus limiting the computational demand. The latter choice was taken in consideration of the fact that the connection of the walls with the slabs and the orthogonal walls appeared solid, and the out-of-plane collapses can be considered in this case as local mechanisms, to be investigated by means of more detailed models of limited portions of structure.

Since the building was subjected to a localized partial collapse of secondary elements (a frescoed mirror vault located in one of the two main halls of the palace), an additional detailed local model of the room was implemented considering a more advanced model accounting for the out-of-plane masonry behaviour $[25,26]$, also in the presence of curved elements $[27,28]$.

The results of both the global and the local models were compared in terms of collapse mechanism with the damage pattern observed in the field. In particular, the detailed local numerical model allowed justifying the partial collapse of the frescoed vault. Finally, a vulnerability assessment of the building in terms of peak ground acceleration (PGA) was performed according to the Eurocode 8 [29,30], as already done with reference to reinforced concrete masonry infilled frames [31]. The procedure was compared with an alternative vulnerability assessment based on nonlinear dynamic analyses conducted on equivalent single degree of freedom systems. Due to the high irregularity of the building an investigation of the direction of the input allowed identifying the main weaknesses of the structure.

The proposed case study not only is a significant example of interpretation of the seismic response of ancient palaces, but the combined use of global simplified and local refined models may represent a more general methodological approach to be pursued in similar circumstances. 


\section{The Case Study: The Gualtieri Building in L'Aquila}

\subsection{Historical and Architectural Description}

The ancient building presently known as Palazzo Gualtieri (also referred to as Palazzo Ximenes-Bonomo), formerly Palazzo Alfieri (then Alfieri-Ossorio), is located in the inner core of the historical centre of L'Aquila, dating back to the Middle Ages. The main façade of the building forms the southern front of Piazza Santa Giusta, an L-shaped public square named after the Romanesque Church of Santa Giusta, free-standing in the north-eastern corner. Palazzo Gualtieri is embedded in a rich context of stately historical architectures, including also Palazzo Centi (western front) and Palazzo Dragonetti (northern front). The main part of the building, denoted as "principal body" in the following, is free-standing on the front, right and back sides, while the left side, facing the so-called Via dei Francesi is partially connected with the coeval adjacent building, characterized by strongly similar structural features and denoted as "secondary body" in Figure 1, where the main part is contoured in blue and the secondary body in red. The structural connection bridging the two buildings, hosting two small rooms at the first and second level, is sustained by a masonry arch, which covers the passageway known as Arco dei Francesi.

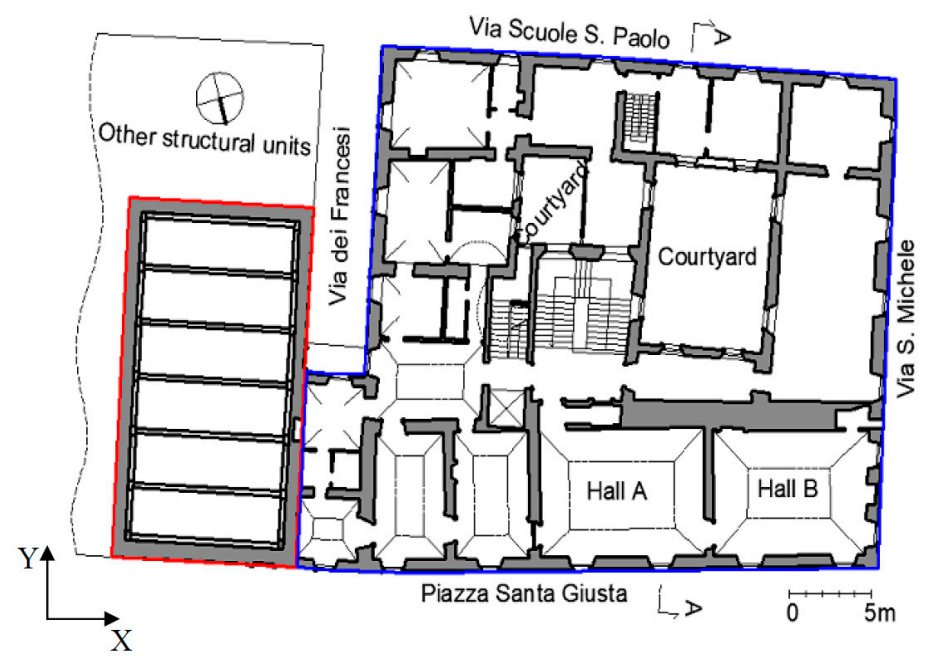

(a)

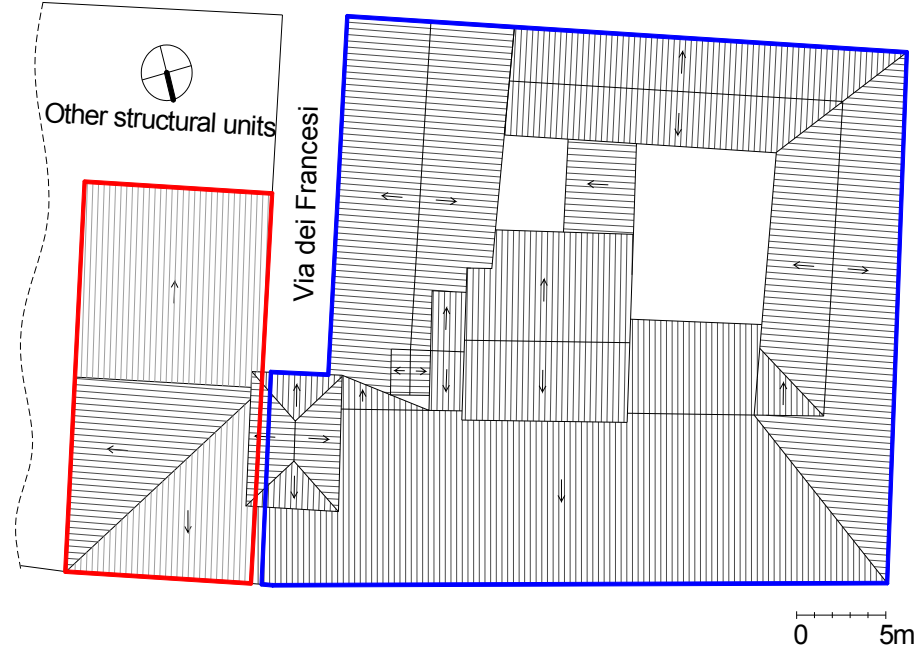

(b)

Figure 1. Plans: (a) of the first level; and (b) of the roof, with indication of the main body of the building (contoured in blue) and of the secondary reinforced concrete body (contoured in red). Reproduced with permission from [18]. 
The building, presently holding different private apartments for residential use, is traced by local historical tradition to the fifteenth century [32]. However, the architectural elements that, in the absence of more reliable documents, allow an approximate dating, that is, window frames and doorways, tend to delay the construction date to the late sixteenth century. The internal courtyard can be dated back to the mid-seventeenth century with sufficient confidence, while minor constructional aspects recall late-Renaissance standards. The two monumental lateral fronts, in particular, are strongly featured by a valuable severe regularity, not tormented by the openings of convenience which have altered the original formal order of the principal façade over the years. In any case, the building -in its original layout-is certainly more ancient than it presently appears due to the architectural additions from the sixteenth and seventeenth centuries. The major historical and architectural value can be undoubtedly attributed to the courtyard. Even if not well-maintained, its original, elegant configuration is still correctly recognizable, and some of the original resistant elements can be clearly identified. Indeed, a regular sequence of thick columns, sustaining round arches, is revealed by decorative lesenes, despite the arcades originally surrounding the court are presently infilled.

\subsection{Past Strengthening Interventions of Structural Retrofitting}

In the early 1990s, the building was interested by an important strengthening intervention of structural retrofitting. However, the ownership fragmentation, together with the recurrent time delay and progressive downsizing of the original plan of structural interventions, caused by continuous reductions of the available financial resources, did not allow an integrated, organic design oriented to the general improvement of the global structural behaviour.

Nonetheless, numerous local interventions allowed the technical solution of the most evident and critical issues, mainly related to, first, the low quality of the rubble masonry, made of an irregular stonework and poor mortar, and, second, deficient connections among orthogonal walls. To this end, large portions of cracked or deteriorated masonry were consolidated with the traditional indenting procedure, many masonry panels were individually strengthened through the jacketing technique, by employing diffuse shotcrete and light steel net reinforcements, while several pairs of weakly-connected orthogonal walls were pinned together with diagonal steel fastening bars. The intervention was drafted according to the recommendations of the Italian national codes in force at the design time [33]. Owing to the historical and architectural importance of the building, the intervention design had to be submitted for preliminary approval to the competent authorities of the Regional board of the Ministry of Cultural Heritage and Environmental Conservation.

In the principal body (Figure 1), the intervention included local demolitions of the masonry walls for the realization of a modern lift shaft (Figure 2a). In particular, a couple of load-bearing walls, adjacent to the ancient staircase, was partially hollowed to host a reinforced concrete box structure. To recover the structural redundancy and simultaneously improve the concrete-masonry cooperation, the new and old structural elements were anchored to each other by means of several stainless steel pins, inserted into holes drilled through the masonry and finally injected with cement grout. To comply with the modified requirements of the new functional distribution, a second staircase was built, with direct access from the courtyard. The reinforced concrete structure sustaining the stairs was built in adjacency to a pair of existing masonry walls (Figure 2a), and properly connected to them through steel fastening pins. Together with these structural modifications, the remaining intervention were driven by the leading idea of improving, as much as possible, the global behaviour of the entire building and all its box-parts. To this purpose, a number of critical issues had to be solved, the most important being a marked loss of verticality of the principal façade, easily recognizable as an out-of-plane deformation of the masonry wall, characterized by an outward arch-shape between the ground and the roof. From a structural viewpoint, this crucial problem was certainly caused by a questionable, non documented, past intervention, during which the original second-level vaulted floor was completely removed to double the internal height of two noble halls at the first level. The consequent absence of any horizontal element able to offer a suitable out-of-plane stiffness was exposing the masonry wall to serious risks of 
overturning. The pre-existence of the problem is also testified by the consequent adoption of different palliative countermeasures over the years, including the addition of abutments and the thickening of the wall base. To mitigate the problem without heavy functional interferences, a light planar frame was realized in adjacency, and then strongly connected to the external face of the masonry wall (Figure $2 b$ ). Thin steel profiles were employed to hide the entire frame in the thickness of the plaster exterior finish. The wall-frame system was finally anchored to the central spine wall of the building by several steel rods (Figure 2c). The poor quality of the rubble masonry, made of irregular calcareous stones with weak adhesive bond, has been extensively treated using non-shrink cement grout injections at low pressure. Although recognized as highly vulnerable, the vaults covering the two noble halls were not object of intervention, due to limited financial resources. A complete overhaul of the roof structures suggested to maintain the existing structural scheme, made of traditional wooden trusses. Several steel ties were added to collaborate with the tensioned rods. A light reinforced concrete ring-beam was realized at the top of the masonry wall to the purpose of anchoring the steel ties (Figure $2 \mathrm{~d}, \mathrm{e}$ ). After careful revision, the large majority of the timbers was maintained in service, with only minor substitutions. The wooden slab sustaining the gable roof was instead entirely replaced, due to its advanced state of deterioration. During the works, an undocumented underground passageway was discovered, running from the building basement toward the Church.

In the secondary body, the structural intervention was generally heavier and affected all the floor levels. In particular, it included the addiction of a new underground level, which required the ground excavation and was founded on a new thick grid of reinforced concrete foundation beams. Reinforced concrete retaining walls were also designed to support the lateral pressure of soil. These retaining walls were orthogonally stiffened by shear walls, and a concrete slab was realized to ensure the structural redundancy. This stiff structural scheme served also as foundation of a self-sustaining three-dimensional reinforced concrete frame, raising up to the roof level, realized in strict adherence to the existing load-bearing masonry walls, and rigidly anchored to them through a system of fastening steel pins at each level. All the columns were abutted to the internal face of the existing masonry walls, and then connected to each other by flat beams at each level, running horizontally at the same height of the keystones of the vaulted floors. At the first level, the barrel vault was consolidated through a typical saddling intervention, consisting in, first, removing of the heavy but incoherent material constituting the original backfill, second, casting a thin curved concrete slab (saddle slab), reinforced by a steel mesh pinned to the vault extrados, third, replacement of the original backfill with light expanded clay aggregate and, finally, covering with a horizontal reinforced concrete slab at the floor level (Figure 2f). At higher levels, some arched and vaulted structures, without significant architectural value, were evaluated as too seismically vulnerable and demolished. The excessive vulnerability was motivated by the evident vertical misalignment of the load-bearing masonry walls, with some arch abutments erected over the vaults of the first floors. Moreover, at the second and third levels, the horizontal thrust forces at the arch and vault springs were poorly confined. Therefore, the vaults were completely substituted with concrete slabs, while the original vaulted shape was formally reconstructed by a plasterboard false ceiling. A ring beam was added at the top of the masonry walls, with the twofold aim of ensuring the structural box behaviour and supporting the new reinforced concrete roof structure. The building has a mean height of about $14 \mathrm{~m}$ and is characterized by an almost rectangular plan, with side lengths of about $36 \mathrm{~m}$ and $28 \mathrm{~m}$, respectively. The courtyard, which is also approximately rectangular, has side lengths of about $7.5 \mathrm{~m}$ and $10 \mathrm{~m}$. A detailed geometric survey is reported in [18]. 

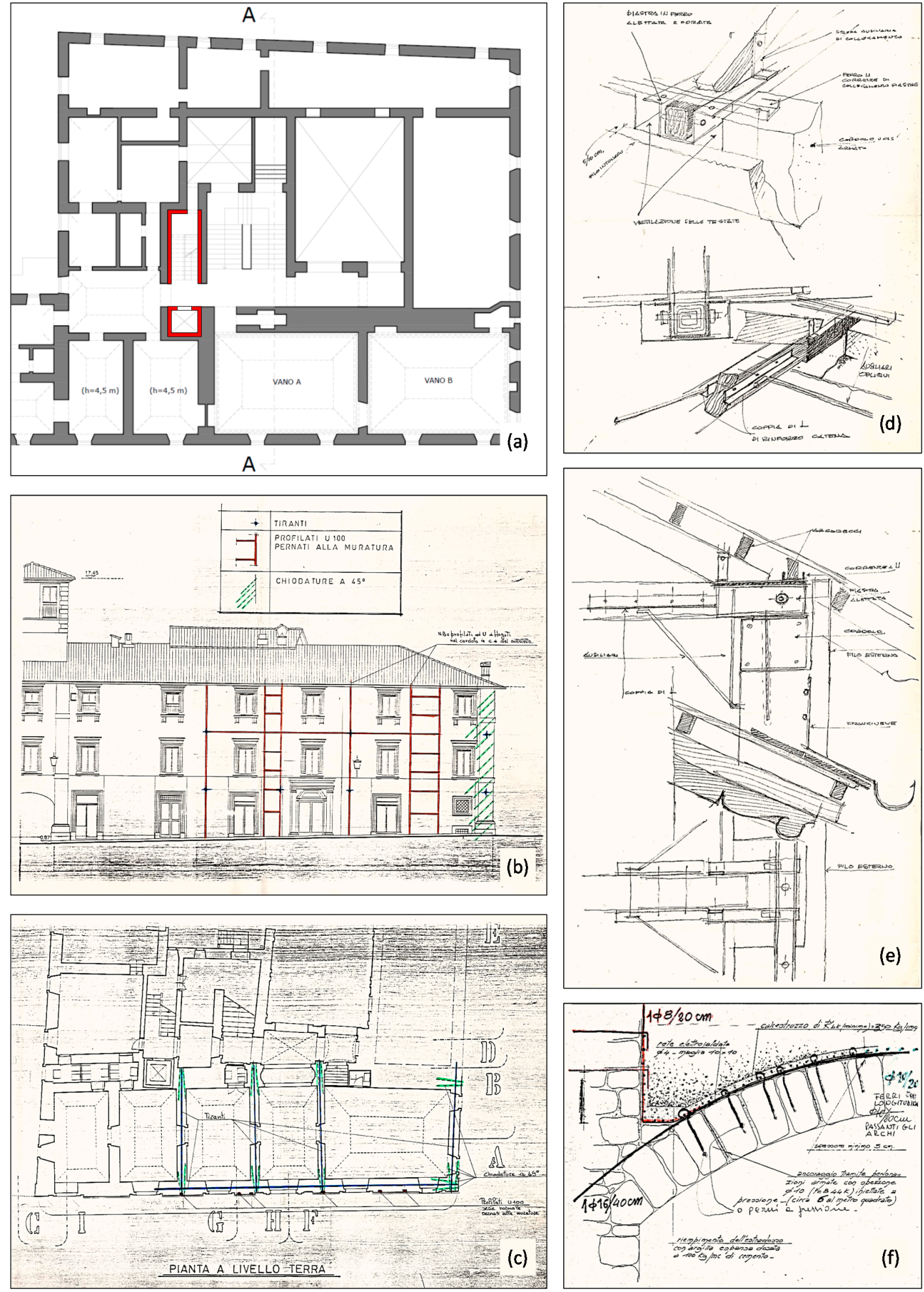

Figure 2. Past strengthening interventions of structural retrofitting (graphical reconstruction and original working drawings): (a) reinforced concrete walls and box structure (red) supporting the new staircase and the lift shaft; (b) light steel frame (red) built in adjacency to the main building façade; (c) steel rods (blue) connecting the light steel frame to the central spine wall and fastening bars (green) connecting some orthogonal walls; (d) technical details of the reinforced concrete ring beam; (e) technical details of the reinforced steel connections between the reinforced concrete ring beam and the wooden trusses supporting the roof; and (f) technical details of the saddling intervention consolidating the barrel vaults. 
During the inspections in the aftermath of the seismic main shock, a direct geometric relief of the building has been done, thus allowing the graphic restitutions of plans, prospects and sections, as well as the crack pattern for each prospect, and the most damaged room [18].

Detailed graphical reconstructions of the northern and western prospects after the main shock are reported in [18], with the corresponding crack patterns; in Figure 1 the plan of the first level and of the roof are reported. Since it was not possible to get access to all the private flats, in case of lack of data, the plans have been reported based on the acquired documents. In Figure 3, the transversal section A-A is reported, and the vaults and structure typologies of the roof are highlighted.

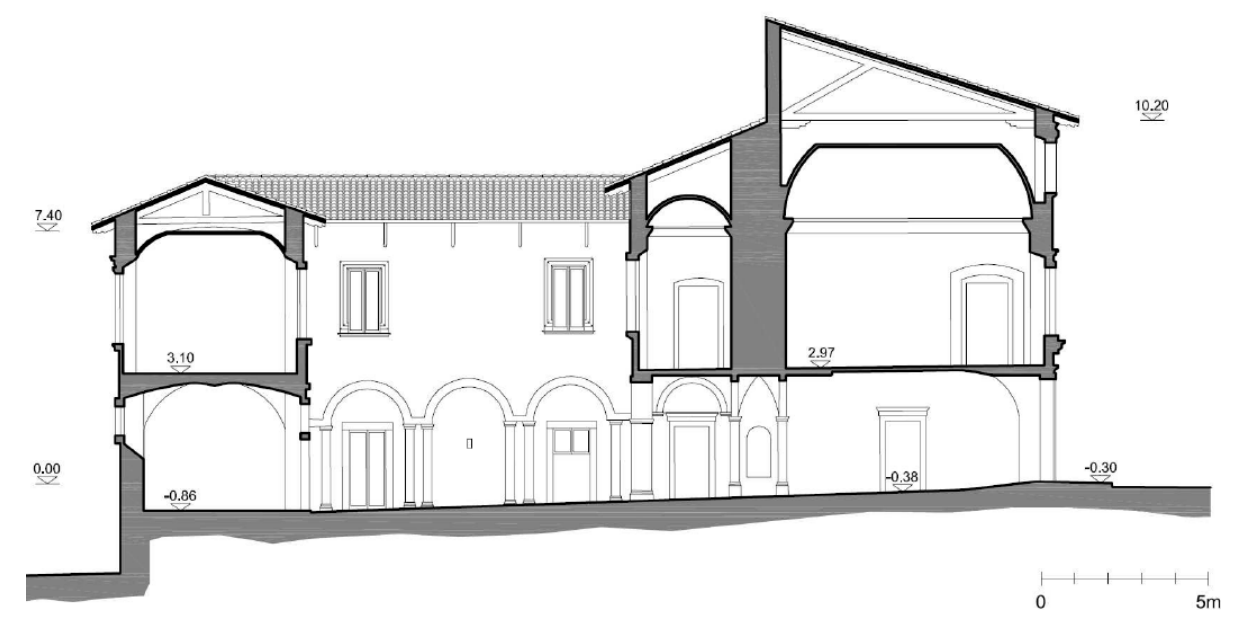

Figure 3. Transversal section (A-A in Figure 1) of the building. Reproduced with permission from [18].

With reference to the large hall at the second level (here called hall B), a high concentration of damage has been observed, both in the perimeter walls, and above all in the surmounting vault, which has partially collapsed (Figure 4). The collapse of the vault represents the main damage of the building, above all for the artistic quality of its frescoes. The wall on S. Michele Street shows severe damage and partial collapse of the masonry medium as well as the loss of the perfect verticality close to the passage of the flue. This hall has been object of specific numerical simulations, the results of which will be described in the following paragraphs.

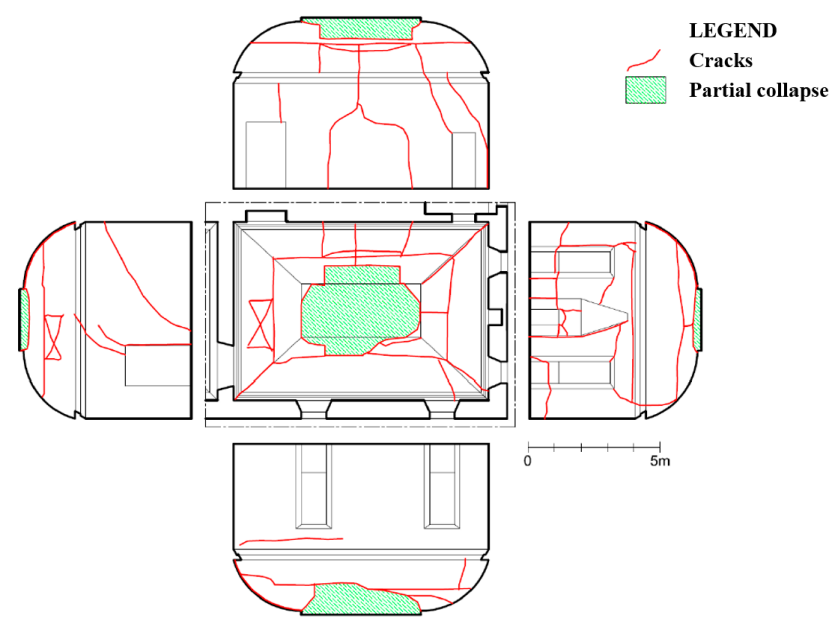

Figure 4. Crack pattern of damaged hall B. Reproduced with permission from [18].

Concerning the masonry media, a visual investigation has lead to the observation of the following characteristics: 
- $\quad$ plastered masonry on the northern and western prospects, and on Via dei Francesi, made of calcareous ashlars with some bricks; on the southern front two different masonry typologies with visible leaf can be observed: the first is partially plastered and made of irregular calcareous ashlars, while the second has also some levelings with bricks (Figure 5);

- $\quad$ corner with ashlars (visible and not perfectly smoothed), with lime mortar (Figure 5);

- $\quad$ widest doors at the first level are surmounted by monolithic lintels, the smallest ones and the windows of the upper levels are surmounted by lintels made of several ashlars and brick arches (Figure 5); and

- vaults of the two halls A and B are made of bricks ordered according to a knife arrangement, with some wooden ribs.
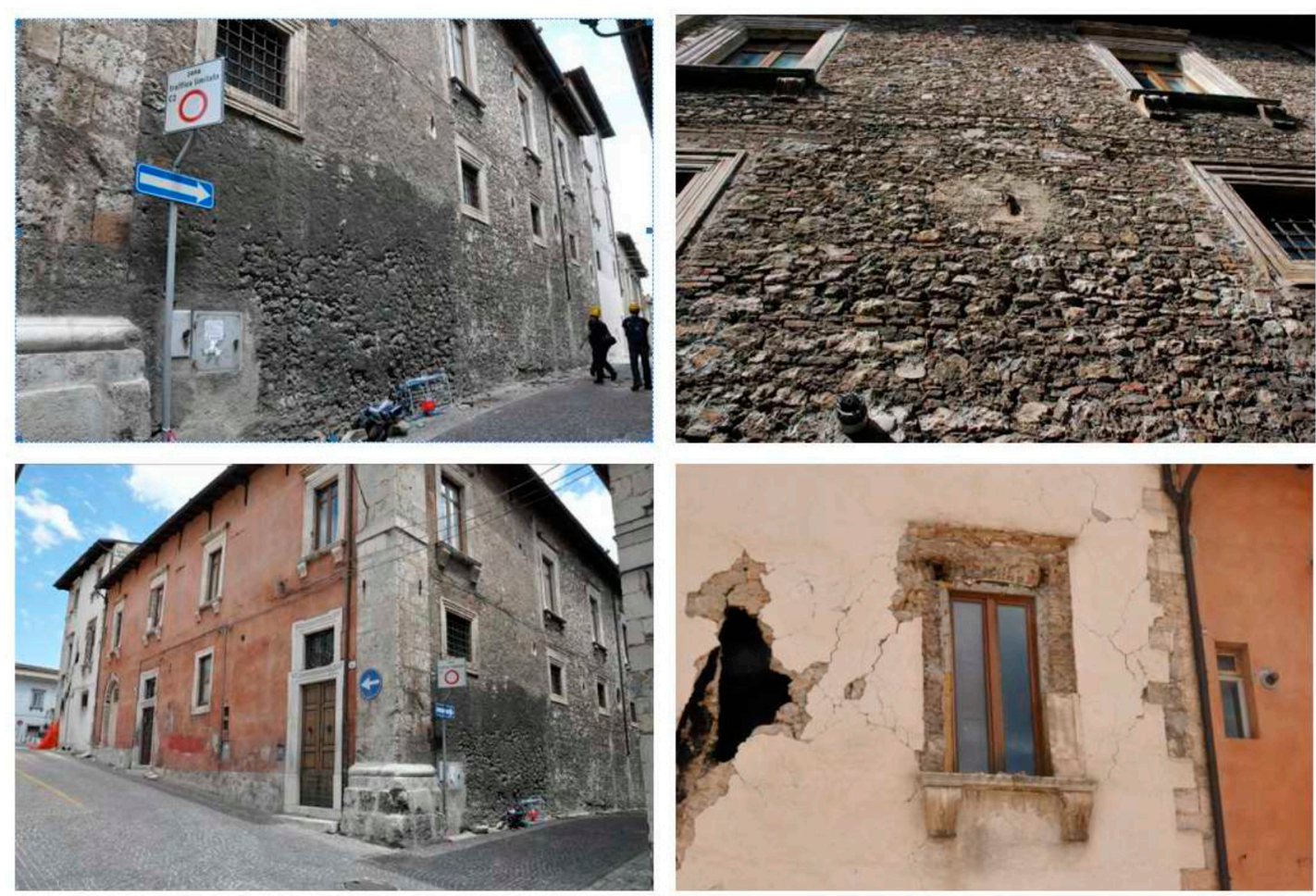

Figure 5. Some details of the masonry typologies. Reproduced with permission from [18].

\section{The Numerical Modelling Approach}

In the following sections, the nonlinear behaviour of the building, until the conventional collapse, is assessed by performing static push-over analyses. To this aim, an innovative discrete element, introduced by Caliò et al. [19], is used. This model, in the original formulation, was conceived for the simulation of the nonlinear in-plane behaviour of unreinforced masonry walls suitable for building with "box behaviour" and then upgraded for modelling infilled frame structures [20-23] and monumental masonry buildings [25-28] in which a complex interaction between in-plane and out-of-plane behaviour is observed.

\subsection{The In-Plane Macro Model}

The in-plane macro model [19] is characterised by a simple mechanical scheme (Figure 6), constituted by an articulated quadrilateral with rigid edges connected by four hinges and two nonlinear diagonal nonlinear links (NLinks). Each side of the quadrilateral can interact with other elements or supports by means of a discrete distribution of the NLinks, denoted as interface. More in detail, 
each interface is constituted by $n$ orthogonal NLinks, and an additional longitudinal NLink, parallel to the panel edge.

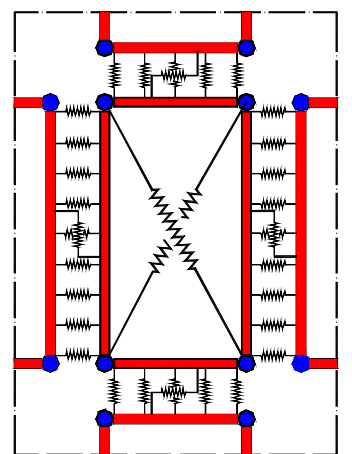

(a)

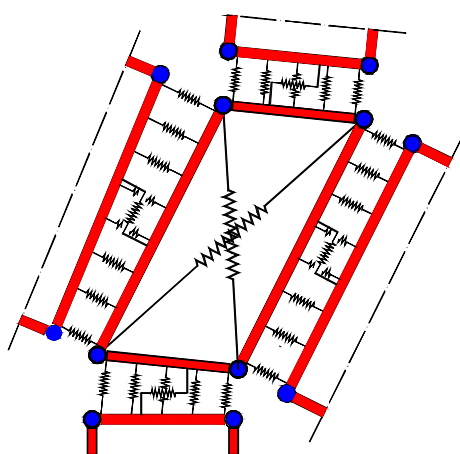

(b)

Figure 6. The basic macro-element for the masonry infill: (a) undeformed configuration; and (b) deformed configuration.

Despite its great simplicity, such a basic mechanical scheme is able to simulate the main in-plane failures of a portion of the masonry wall subjected to in-plane horizontal and vertical loads. These well-known collapse mechanisms, namely the flexural failure, the diagonal shear failure and sliding shear failure, are approximately represented in Figure 7, where the typical crack patterns, together with the qualitative kinematics of the masonry portion, are also sketched. Figure 8 shows how the proposed macro-element allows a simple and realistic mechanical simulation of the corresponding failure mechanisms of a masonry wall in its own plane.

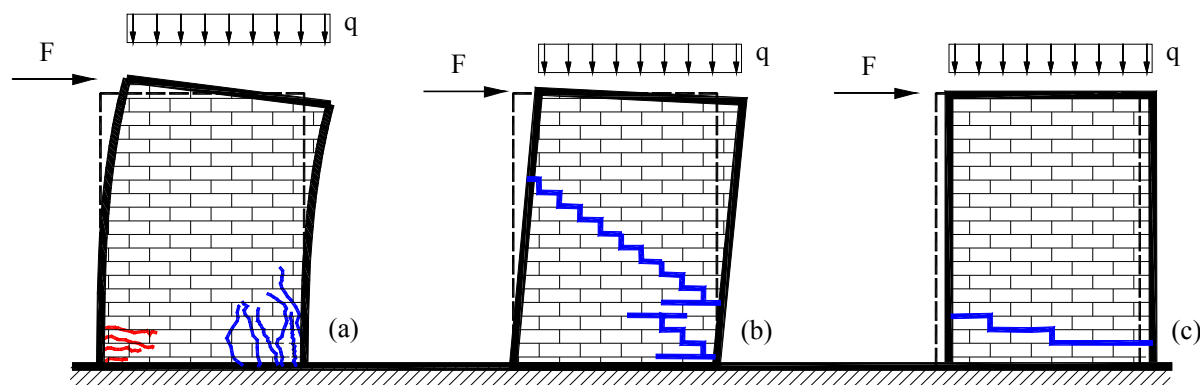

Figure 7. Main in-plane masonry failure mechanisms: (a) flexural; (b) shear-diagonal; and (c) shear-sliding.

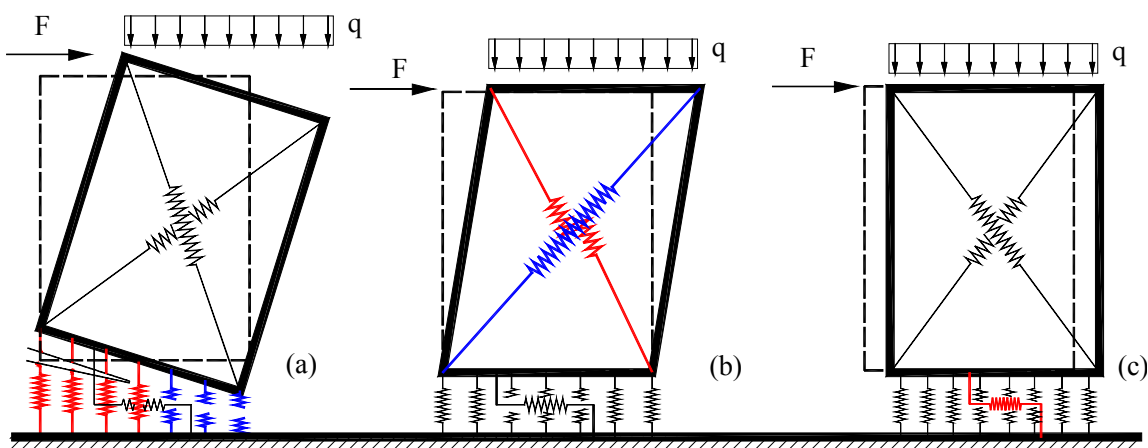

Figure 8. Simulation of a masonry portion collapse mechanisms by means of the macro-element of the in-plane mechanisms: (a) flexural; (b) shear-diagonal; and (c) shear sliding. 
Each discrete element is endowed with three degrees of freedom, associated to the in-plane rigid-body motion, and a further degree of freedom, needed for the description of the shear deformability. The deformations of the interfaces are associated to the relative motion between adjacent panels, therefore no further Lagrangian parameter has to be introduced in order to describe their kinematics. Figure 9 shows how a simple masonry wall can be modelled by means of the proposed modelling approach.
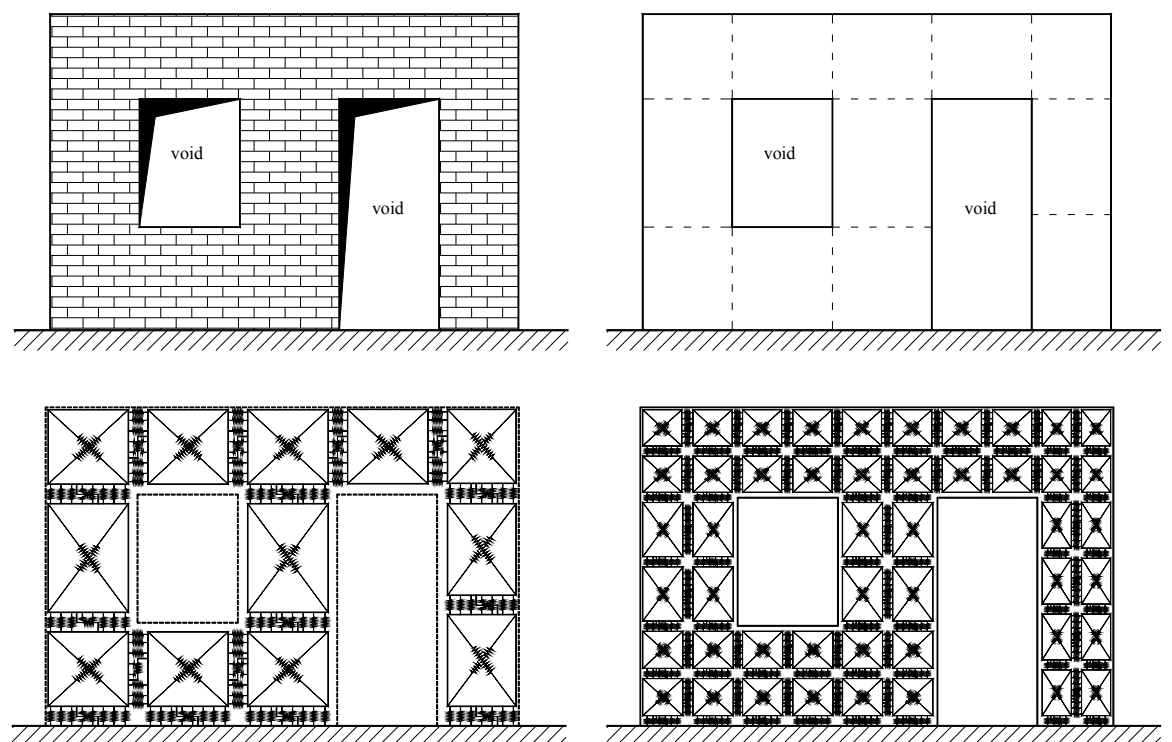

Figure 9. An example of a plane masonry wall and corresponding macro-element discretizations with different mesh resolutions.

The effectiveness of the simulation of the nonlinear behaviour relies on a suitable choice of the mechanical parameters of the model inferred by enforcing an equivalence between the masonry media and a reference continuous model characterised by simple but reliable constitutive laws. This equivalence is based on a straightforward fibre calibration procedure, and is based only on the main mechanical parameters that characterise the masonry according to an orthotropic homogeneous medium [19]. It is worth noting that each macro-element inherits the plane geometric properties of the corresponding modelled masonry portion; consequently, different from the simplified models based on equivalent strut element approaches, the definition of an effective dimension of the element is not needed. For mixed masonry-reinforced concrete structures, beam-column lumped plasticity elements are included in the model. Frame elements interact with the adjacent masonry, along the entire contact length, by means of the interfaces.

Each element of the frame interacts with the masonry infill by means of the Nlinks distribution along the macro-element interfaces. For each interface, a general layout discretization, of $n$ orthogonal and single longitudinal NLinks, has been considered. The nonlinear behaviour of the frame element is modelled by rigid-plastic hinges occurring along the beam span at different cross sections. The inelastic behaviour of the element, concentrated at the rigid-plastic hinges, is governed by the interaction of the axial force and two bending moments consistent with yielding surfaces of the concrete cross sections. Once the constitutive laws have been defined, both force and displacement controlled static processes can be performed according to the procedures currently used in finite element analyses. The model here briefly described is implemented in the dedicated software environment 3DMacro.

\subsection{The Model for Curved Masonry Structures}

The macro-element for curved masonry structures is an extension, to the case of shell structures, of a three-dimensional rectangular macro-element proposed for the simulation of the seismic response 
of masonry buildings [25] (Figure 10b), able to model the out-of-plane behaviour of masonry walls, which, in turn, is an extension of the previously described plane model (Figure 10a). The rectangular element reported in Figure 10b has been conceived to simulate the mechanical behaviour of masonry walls when subjected both to in-plane and to out-of-plane loadings. It is represented by a simple mechanical scheme consisting in a rectangular quadrilateral with rigid edges and hinged vertices connected by diagonal NLinks which simulate the in-plane shear deformability of the corresponding masonry macro-portion. The quadrilateral can interact with other elements along each rigid layer edge by means of a discrete distribution of NLinks with limited tensile strength. Each interface includes NLinks orthogonal to the rigid edges, which govern the in-plane and out-of-plane flexural behaviour of the element, and NLinks parallel to the edges able to simulate the in-plane and out-of-plane sliding and torsional behaviour. In particular, the stiffness of these out-of-plane sliding links are calibrated according to the out-of-plane shear stiffness of the panel, their yielding dominia are associated to friction phenomena, and the relative distance is set in order to guarantee an elastic torsion equivalence with the corresponding continuum [25]. As a consequence, the ultimate strength dominium which governs the interaction between torsion and out-of-plane shear response, results linear as shown in [25]; however, more effective models with regard to torsion-shear interaction and its influence in the out-of-plane mechanisms can be found in the literature [34-36]. The kinematics of the element is governed by seven degrees of freedom able to describe both the rigid body motion and the shear deformability of the base element.

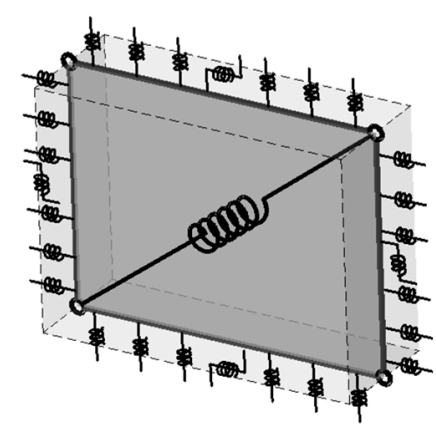

(a)

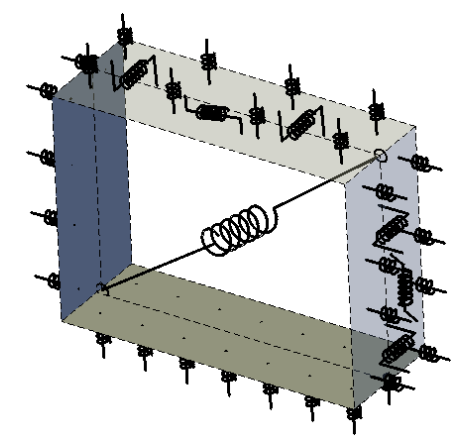

(b)

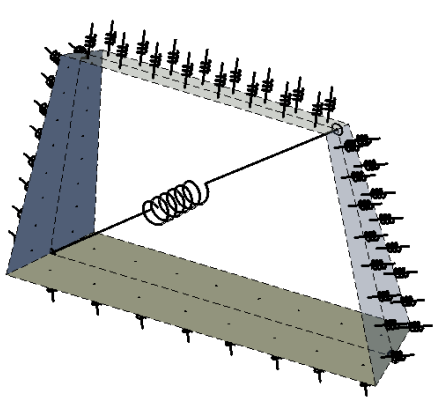

(c)

Figure 10. Layout of the macro-element at its three stages: (a) plane element; (b) spatial regular element; and (c) three-dimensional element for curved structures.

The discrete element conceived to model shell masonry elements [27,28,37] represents an extension of the rectangular element and is constituted by an articulated quadrilateral whose geometry is not regular in order to allow the meshing of a generic curved surface with macro-elements (Figure 10c). Each macro-element is still characterized by four rigid edges whose orientation and dimension are associated to the shape of the element and to the thickness of the portion of modelled masonry that is represented. A diagonal NLink simulates the shear deformation of the quadrilateral in its own average plane, while spatial interfaces govern the interaction with the adjacent elements or with the external supports. These interfaces are in general skew with respect to the average plane of the element, and their motions are ruled by a discrete number of NLinks. Each quadrilateral is defined by the geometric coordinates of his vertexes, the four normal unit vectors to the surface and the thicknesses in correspondence of these points.

If the geometric data and the mechanical characteristics of the masonry media are known, the properties of the equivalent macro-element, corresponding to the part of the masonry portion modelled, can be established through a fibre calibration procedure. 


\section{The Numerical Simulations}

In order to assess the global response of the building, a three-dimensional numerical model of the entire structural complex has been developed in the software environment 3DMacro in which the 2D macro-model previously described is implemented; in Figure 11, two axonometric views of the global building are reported. In the numerical model the structural transformations and the recent seismic retrofits provided to the building have been considered. The main aim of the retrofitting interventions made in the 1990s was to prevent the major causes of collapse in masonry buildings, that is the out-of-plane failures. In particular, the insertion of the light reinforced concrete beams and of tie rods (to eliminate the thrusts of the sloping roof and of the vaults), the demolition and reconstruction of numerous slabs and the improvement of the connection of orthogonal walls, guaranteed a global box behaviour of the building, as demonstrated by the overall response exhibited during the earthquake of 2009. For the latter reason, in the global modelling the plane model described in Section 3.1 was employed, assuming the hypothesis of box behaviour of the building. In addition, in the secondary body of the building, beyond the "Arco dei Francesi", the recent reinforced concrete frame, as well as the stiffening effect of the new slabs, have been modelled.

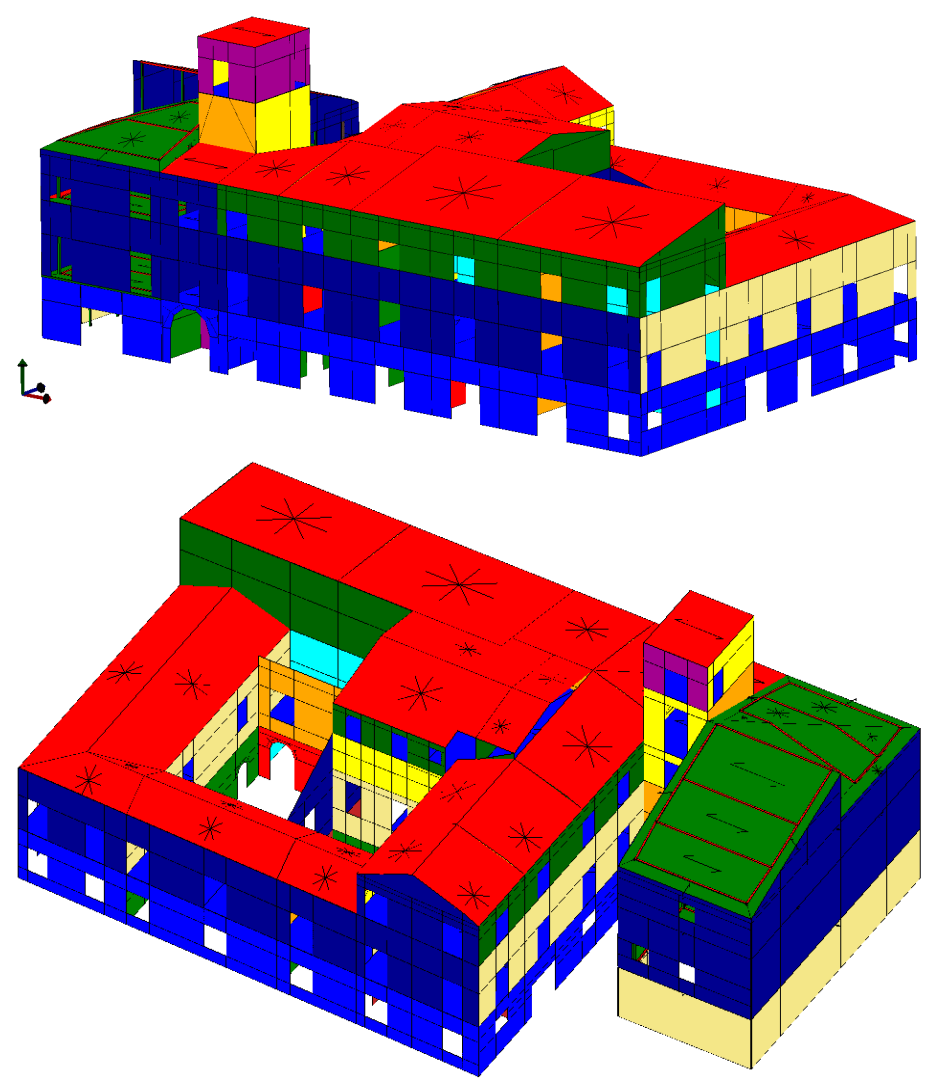

Figure 11. Computational model: axonometric views.

The building is characterized by a wide variety of masonry typologies as well as different masonry thicknesses according to the level of the walls and their age of construction. Furthermore, since the building has been growing in the last 400 years, a significant geometry complexity can be encountered. In particular, in Figure 11, the colours are associated to the thickness of the walls directly observed on the field (which ranges from $25 \mathrm{~cm}$ at the top of the tower to $100 \mathrm{~cm}$ at the first level).

Since no "ad hoc" in situ investigation has been possible to characterize the mechanical properties, they have been calculated according to the Italian Code [38], based on the masonry typologies detected during the relief. In particular the rubble masonry was considered for all the vertical elements since 
this masonry typology seemed to be the most appropriate and close to all the typologies present in the building. The localized interventions on the masonry walls, made in the occasion of the recent structural retrofit of the building, aimed at reinforcing the weakest parts of the structure in order to make uniform the structural strengths within the building. This reason has led the authors to consider a single set of mechanical properties for all the walls. On the other hand, the frescoed vaults of the two noble halls were not object of any structural improvement and, as demonstrated by the partial collapse of one of them, they turned out to be the most vulnerable parts of the building, involving the in-plane and out-of-plane behaviour of the masonry elements. For the detailed model of the hall, a different set of mechanical properties was assumed for the vault, since it was made of bricks; to this purpose, the relevant masonry typology of the Italian Code [38] was considered. In all the considered cases, the strengths have been divided by the confidence penalty factor indicated in [38] and associated to the lowest level of knowledge of the structure (LC1). In Table 1, the mechanical properties of both the considered masonry typologies are reported. The mechanical properties of recent parts of the building (reinforced concrete frames) have been assigned according to the strengthening design. In particular, the concrete typology belongs to the Rck25 class, whereas the bar steels are of FeB44k type.

Table 1. Mechanical properties of the masonry adopted in the numerical model.

\begin{tabular}{ccccccccc}
\hline Masonry Typology & $\mathbf{E}(\mathbf{M P a})$ & $\mathbf{G}(\mathbf{M P a})$ & $\boldsymbol{\tau}_{\mathbf{0}}(\mathbf{M P a})$ & $\boldsymbol{\sigma}_{\mathbf{c}}(\mathbf{M P a})$ & $\mathbf{G}_{\mathbf{c}}(\mathbf{N} / \mathbf{m m})$ & $\boldsymbol{\sigma}_{\mathbf{t}}(\mathbf{M P a})$ & $\mathbf{G}_{\mathbf{t}}(\mathbf{N} / \mathbf{m m})$ & $\mathbf{w}\left(\mathbf{k N} / \mathbf{m}^{\mathbf{3}}\right)$ \\
\hline Masonry walls & 690 & 230 & 0.02 & 1.0 & 0.1 & 0.05 & 0.02 & 19 \\
Vault & 1200 & 480 & 0.04 & 3.0 & 0.3 & 0.1 & 0.05 & 19 \\
\hline
\end{tabular}

The area loads on the slabs have been calculated considering as own weight that obtained according to the slab typologies detected in situ, while the overload has been calculated according to the Italian Code [38], considering the use destination of each room. A reinforced concrete slab typology was observed, with a thickness of $20 \mathrm{~cm}$ (green in Figure 12 with a self weight of $2.77 \mathrm{kN} / \mathrm{m}^{2}$ ), slabs characterized by surmounting masonry vaults (blue in Figure 12 characterized by a self weight equal to $5 \mathrm{kN} / \mathrm{m}^{2}$ ) and the wooden roof (red in Figure 12, self weight equal to $5 \mathrm{kN} / \mathrm{m}^{2}$ ). The vaults are modelled according to a deformable isotropic plate whose thickness is equal to the vault thickness, and whose Young's modulus corresponds to the one adopted for the masonry vaults (that is $1200 \mathrm{MPa}$ ). The seismic weight of the building has been estimated in about $58.580 \mathrm{kN}$.

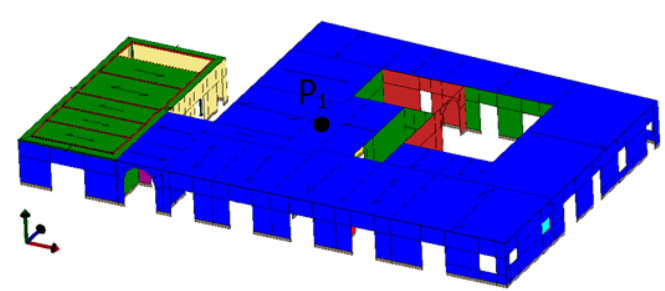

(a)

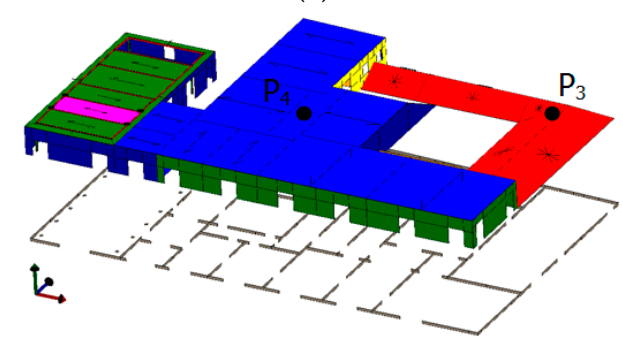

(c)

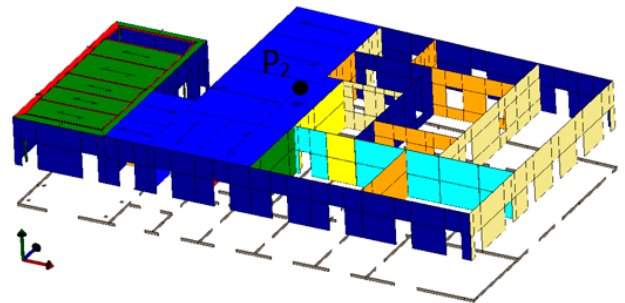

(b)

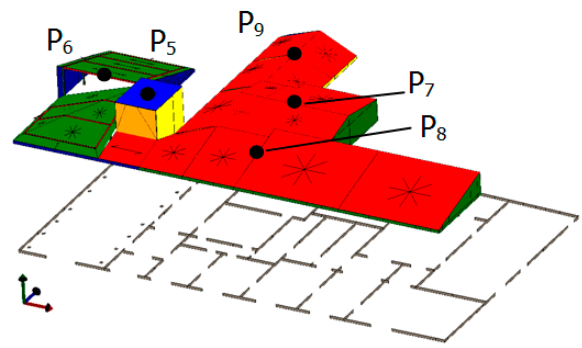

(d)

Figure 12. Control points scheme; (a) First level: $3.50 \mathrm{~m}$; (b) Second level: $7.50 \mathrm{~m}$; (c) Third level: $10.20 \mathrm{~m}$; (d) Fourth level: $14.45 \mathrm{~m}$. 
To assess the seismic capacity of the building nonlinear static analyses have been considered according to a mass proportional force distribution. The structural masses and the additional masses due to the gravity loads are considered distributed in the model in the actual positions. A set of ten control points has been chosen according to Table 2, where the relevant identifiers Id are riported as well, and summarized in the scheme reported in Figure 12. The displacement of each control point is monitored during the push-over analyses.

Table 2. Control points of the building.

\begin{tabular}{|c|c|c|c|}
\hline Id & Level (m) & Description & Mass (t) \\
\hline P1 & 3.50 & First Level & 2541.9 \\
\hline $\mathrm{P} 2$ & 7.50 & Second Level & 1410.5 \\
\hline $\begin{array}{l}\text { P3 } \\
\text { P4 }\end{array}$ & 10.20 & $\begin{array}{l}\text { Pitched roof } \\
\text { Plan floor }\end{array}$ & 1070.9 \\
\hline $\begin{array}{l}\text { P5 } \\
\text { P6 } \\
\text { P7 } \\
\text { P8 } \\
\text { P9 }\end{array}$ & 14.45 & $\begin{array}{c}\text { Tower } \\
\text { Reinforced concrete part } \\
\text { Central pitched roof } \\
\text { Frontal pitched roof } \\
\text { Rearward pitched roof }\end{array}$ & 689.4 \\
\hline P10 & 17.75 & Tower & 31.7 \\
\hline
\end{tabular}

The vulnerability assessment process has been performed according to the N2 [39] method. A mass is assigned to each control point considering a volume of influence of the structure (see Table 2); the entire structure is simplified considering a nonlinear single degree of freedom system obtained from the capacity curves and the corresponding mass distribution of the adopted control points. A further simplification is then performed, thus allowing to consider an equivalent elastic perfectly plastic system, which is calibrated according to the Italian code [38] for the vulnerability assessment.

The set of control points was chosen in order to be representative of the mass distribution within the building and to grasp effectively the collapse mechanisms and torsion effects that can occur during the analysis. The choice of the control points is a crucial aspect when nonlinear static analyses are employed and a simplified vulnerability assessment procedure is adopted, as done on this study. On the contrary, nonlinear dynamic analyses do not require the definition of any specific control point, but they still seem to be too numerically cumbersome for such complex structures, especially with reference to practical engineering purposes.

All floors have been considered deformable in the model according to an orthotropic elastic plate (except those corresponding to the vaults which are considered isotropic), and the corresponding mechanical properties were computed according to their actual geometry. Only the recently introduced reinforced concrete slab has been considered rigid. During the analysis, the current displacement of each control point is obtained as the average value of the displacements of all the points of the pertinent area associated to the control point (Figure 12).

\subsection{Global Behaviour of the Building}

Since the building is highly irregular, its actual response may be significantly influenced by the input direction. With the aim of investigating the influence of the input direction on the seismic response of the building, 12 nonlinear static analyses were performed varying the input direction according to an angular step of $30^{\circ}$. The orientations of the analyses are referred to the main direction of the building ( $\mathrm{x}$ direction in Figure 13), while the direction $90^{\circ}$ is referred to the $\mathrm{Y}$ direction. The conventional collapse occurs, for each analysis, with the achievement of a reduction of the base shear of the $20 \%$ with respect to the maximum base shear. The maximum base shear coefficients 
in the analyses range between 0.13 and 0.20 , while the maximum displacements range between $5 \mathrm{~cm}$ and $7 \mathrm{~cm}$ (Figure 13).

In terms of collapse mechanisms they seem to be quite global; however, along the longitudinal direction the damage pattern at collapse mainly involves the spandrels at each level with a base rotation of the piers (which is consistent with the observed crack pattern observed in the field), while in the transversal direction the collapse occurs with the shear failure of the piers at the base level (Figure 14).

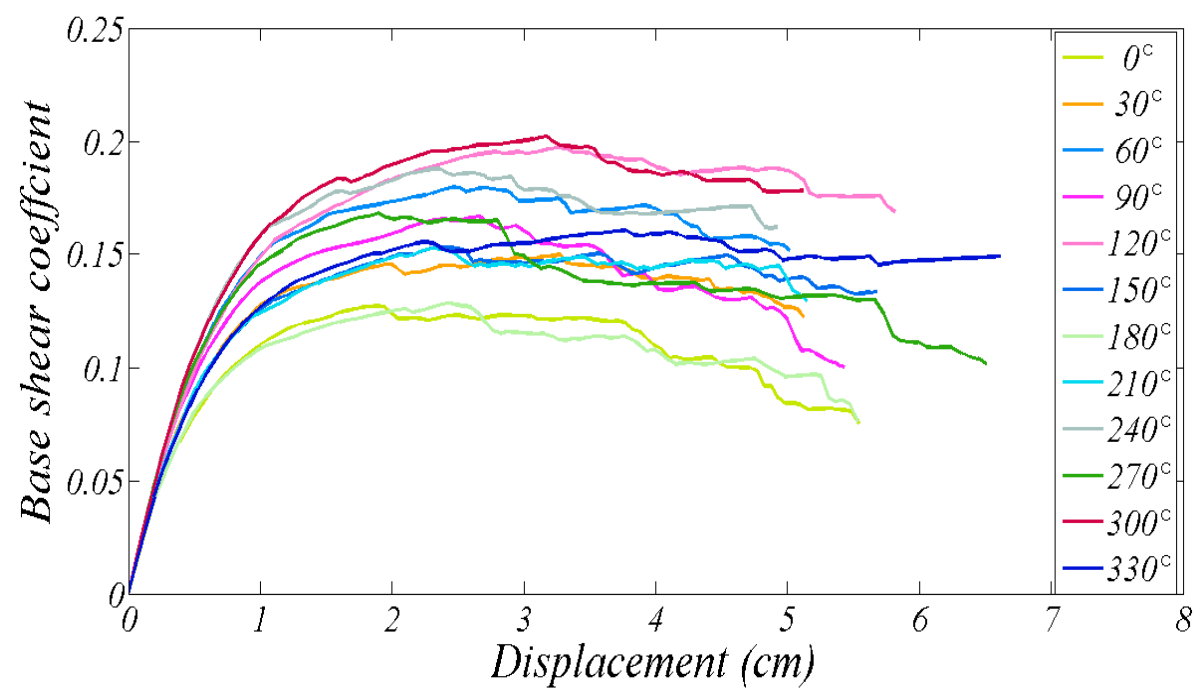

Figure 13. Capacity curves summary.
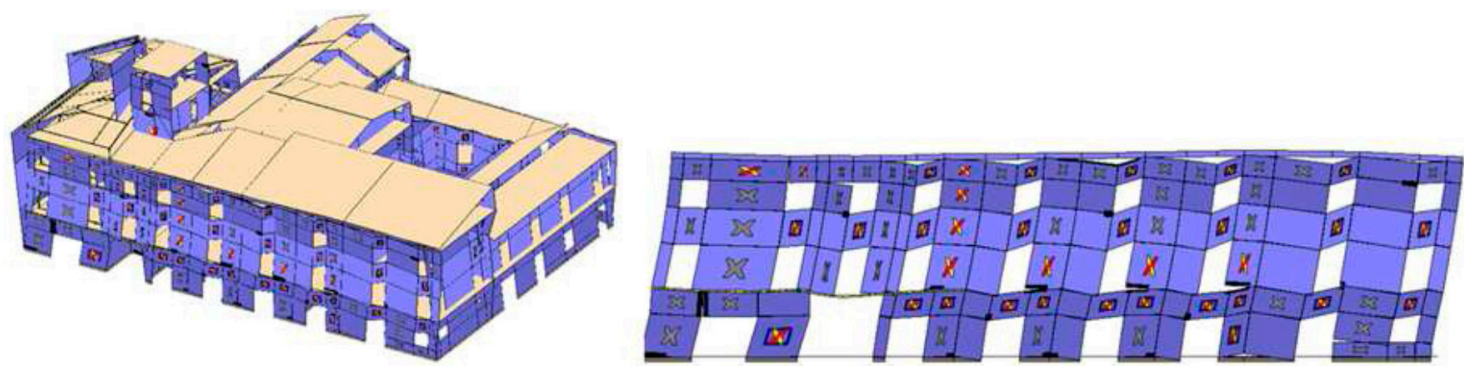

(a)
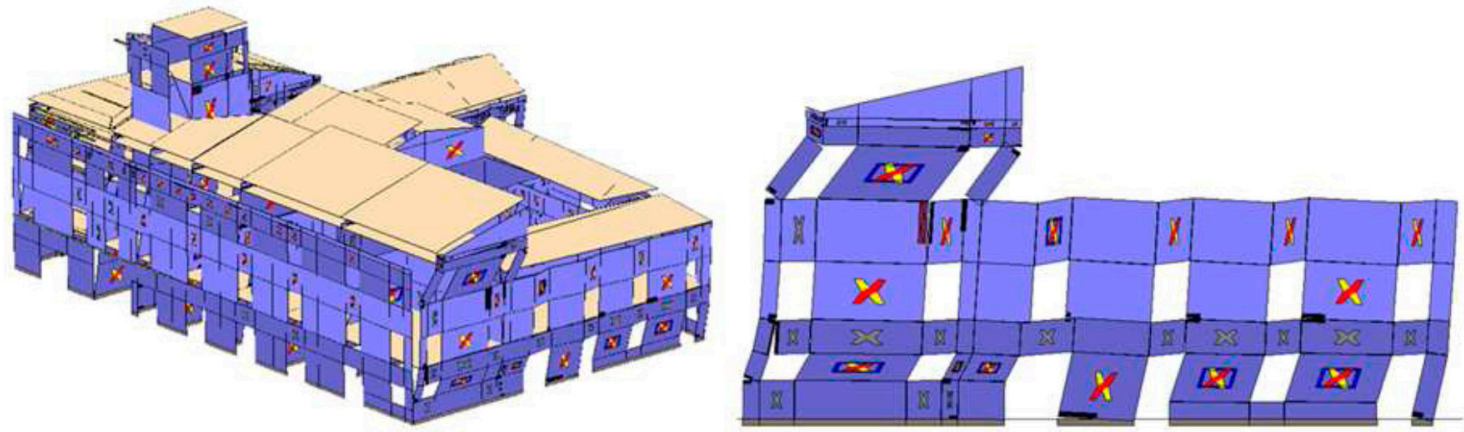

(b)

Figure 14. Collapse mechanisms: (a) longitudinal; and (b) transversal directions.

The pushover curves obtained for the different loading directions can be synthetically represented by means of the three-dimensional capacity dominium, plotted in a reference system $X Y Z$, in which $X$ and $Y$ identify the two main directions of the building. In such a 3D plot (Figure 15), each push-over curve is represented along the input direction, in a plane perpendicular to the XY plane, so that the 
base shear coefficient (computed as global base shear divided by the weight of the building) is reported in the $\mathrm{Z}$ axis. Such a representation allows easily identifying the overall resistance and ductility of the building along all the investigated directions in a unified representation and it has the great advantage of favouring a quick and easy identification of the strongest and weakest directions of the building as well as the most brittle and ductile. The level of resistance is represented in a colour scale. For those intermediate directions that have not been specifically investigated, they have been linearly interpolated. The ductility of the structure in all the investigated directions is also readable in the graph. The presence of the central hole in Figure 15 represents a measure of the fragility of the system along each load direction. In the considered applications, the origins of all the pushover curves are set at a distance equal to $1.2 \times u_{\max }$, being $u_{\max }$ the maximum achieved displacement among all the performed analyses. This way, the more a certain curve approaches the centre of the hole, the highest displacement capacity the structures possesses in that direction.
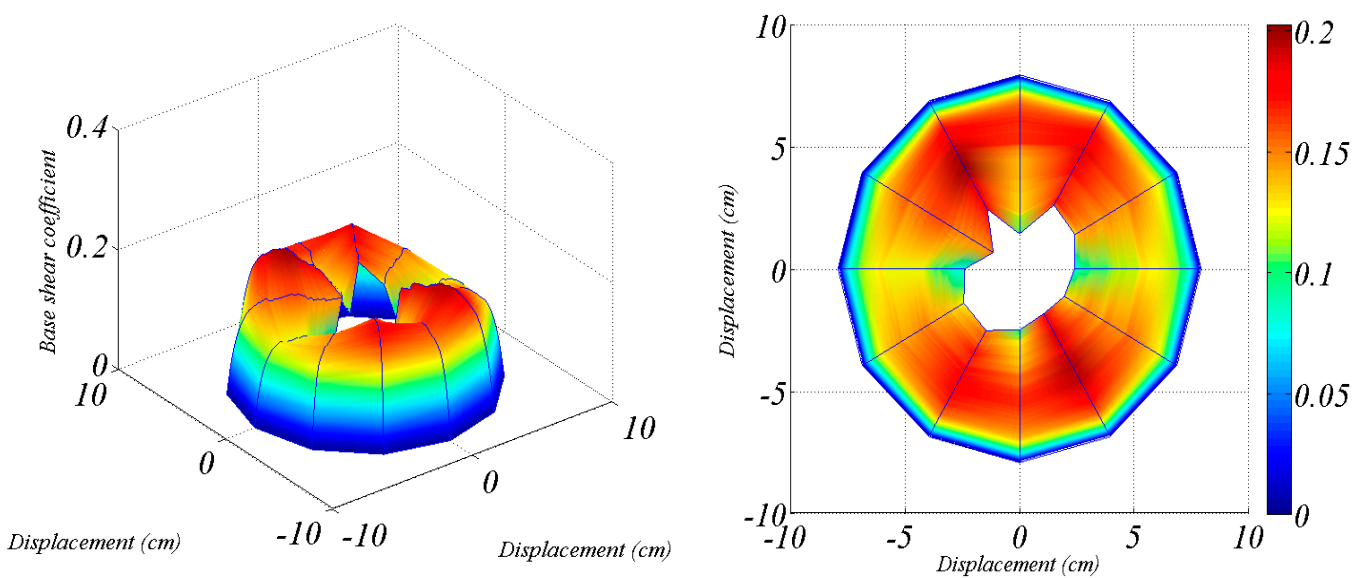

Figure 15. Capacity dominium.

\subsection{The Local Response of the Noble Hall}

The most significant damage occurred at the two halls at the second level of the building, surmounted by two mirror vaults, whose horizontal parts are frescoed. Both the vaults have suffered heavy damage, and the central frescoed part of the vault in hall B (according to the plan in Figure 1a) has fallen because of the earthquake, as shown in the pictures in Figure 16. To reproduce by means of numerical simulations the crack pattern observed, a numerical model of the hall has been implemented considering the perimeter walls and the surmounting vault, Figure 17.
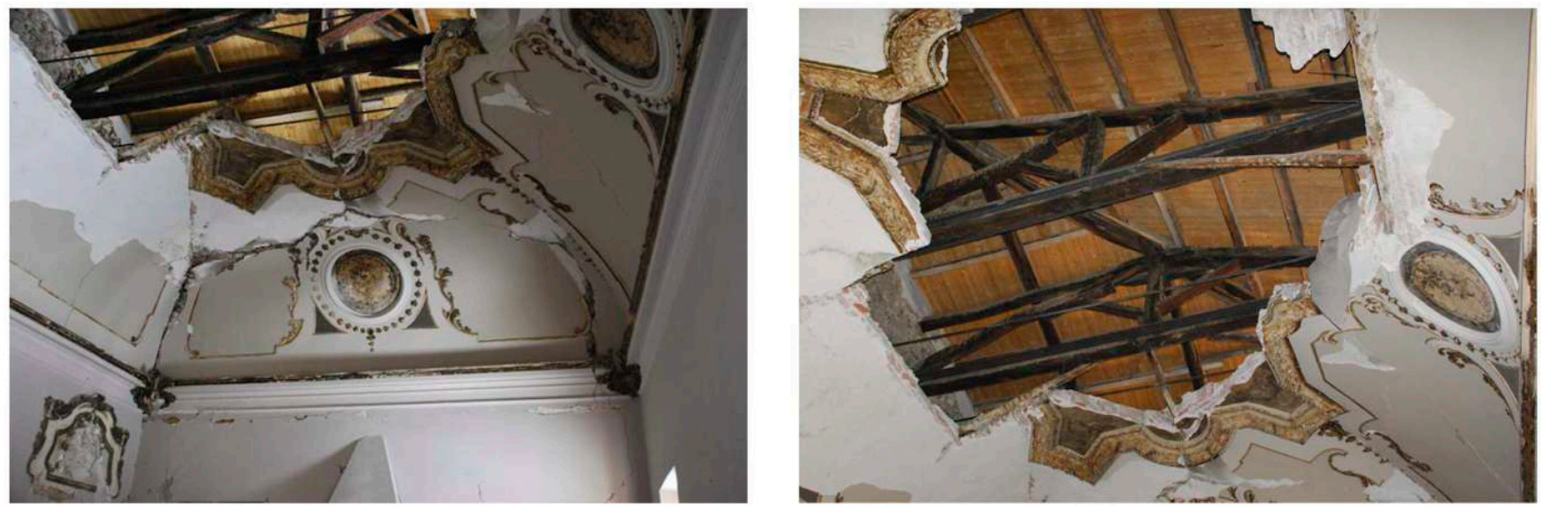

Figure 16. Pictures of the partially fallen vault. 


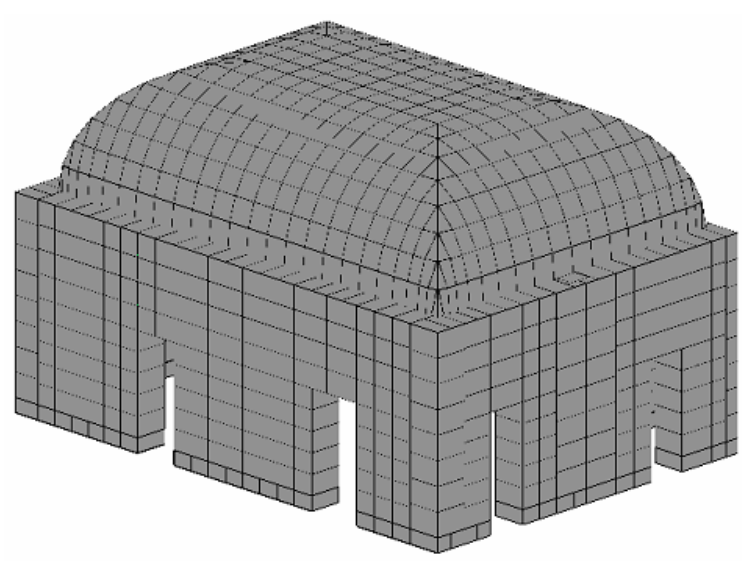

Figure 17. Axonometric view of the numerical model.

In particular, three different load directions have been considered, namely the vertical one (push down) and the two horizontal directions, applying a mass proportional load distribution. For the horizontal load distributions, the two main directions according to the plan of the room have been considered.

The results of the analyses have been reported in terms of collapse mechanisms and capacity curves. The capacity curves report the total base reaction, normalized by the total weight (estimated in $2230 \mathrm{kN}$ ), versus the top displacement of the vault. The mechanical properties of the masonry assumed in the numerical simulation are reported in Table 1. It is worth to note that the nonlinear static analyses do not aim at providing a complete vulnerability assessment of the vault, but rather to better understand and justify the collapse of the vault. In fact, a proper vulnerability assessment could not neglect the interaction of the considered structure with the contouring structural elements; in addition, the hall is located at the second level of the building and the filter effect of the first level of the palace should be considered for a reliable vulnerability assessment.

For all the considered load directions, a mass proportional force distribution has been considered. In Figure 18, the collapse mechanisms for all the considered analyses are reported. In particular, in Figure 18a, the collapse mode associated to the vertical mass distribution is reported; as expected the intrados of vaults suffers in the central part, whereas at the extrados the damage is concentrated on a wall of the hall, that surmounts a chimney, where the thickness of the wall is locally much lower (200 mm against $700 \mathrm{~mm}$ of the rest of the wall). In Figure 18b,c, the collapse mechanisms associated to the horizontal load distributions are reported; for these load distributions, the base of the vault tends to suffer the heaviest damage, but the chimney represents a weak part of the hall for these load conditions as well, demonstrating that the cause of the partial collapse of the vault must be probably associated to this element. This hypothesis is also supported by the fact that the twin hall (in which no chimney is present) did not suffer the collapse of the vault.

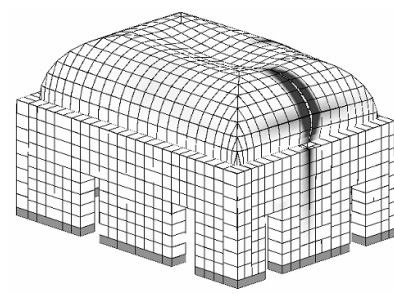

(a)

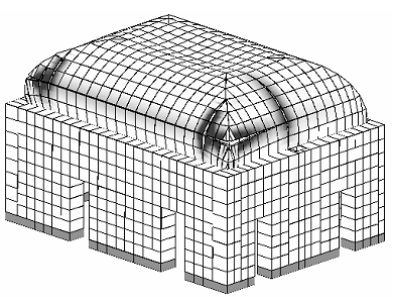

(b)

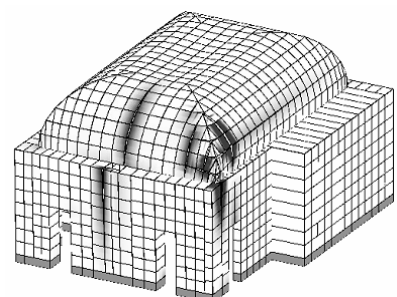

(c)

Figure 18. Collapse mechanisms of the mirror vault corresponding to the application of: vertical actions (push down analysis) (a); and horizontal actions (push over analyses, along the: longitudinal (b); and transversal direction (c). 
In terms of capacity curves, the results are shown in Figure 19. In each analysis, the maximum displacement along the direction of the loads is considered as monitored displacement. As generalized force parameter, the global vertical base reaction normalized by the weight of the considered portion of the structure is considered for the push-down and the base shear coefficient is considered for the two horizontal push-over analyses.

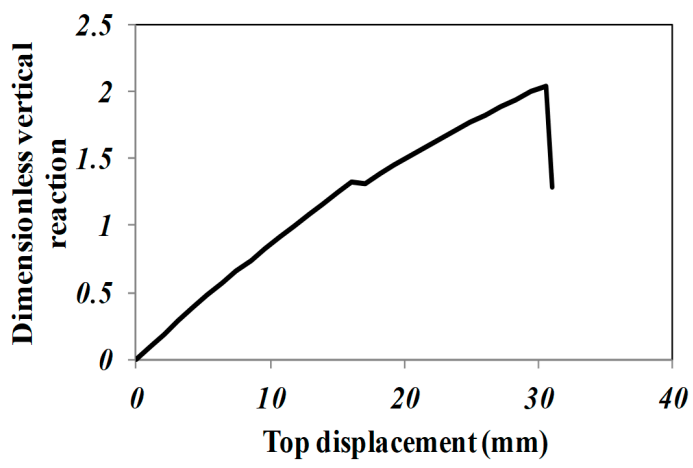

(a)

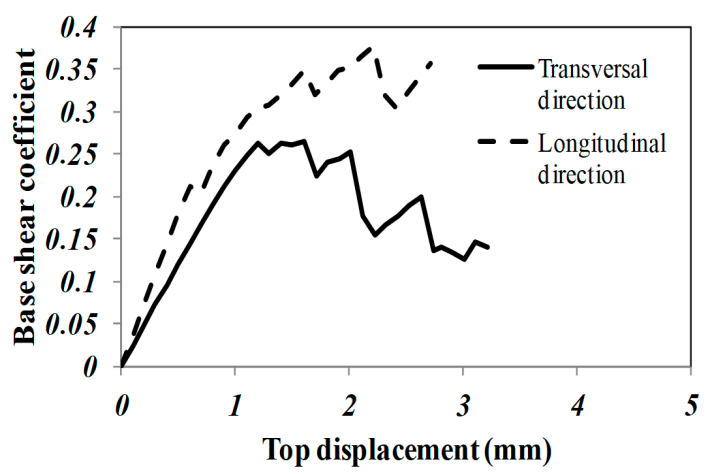

(b)

Figure 19. Capacity: (a) vertical; and (b) horizontal directions.

With regard to the vertical load distribution, the salon exhibits an overstrength with respect to the static condition equal to 2.03 , but the global behaviour is brittle, thus making the hall very vulnerable to the vertical component of the earthquake. The capacity curves associated to the horizontal directions have a very low level of displacement capacity (less than $4 \mathrm{~mm}$ ); the transversal direction has a lower level of strength (maximum base shear coefficient 0.25 ) and a more pronounced softening branch with respect to the longitudinal direction (maximum base shear coefficient 0.35 ).

\section{Global Seismic Assessment}

In order to assess the seismic safety of the building, in this section two alternative procedures for the evaluation of the seismic performance of the building are presented. In both cases, the role of the direction of seismic input is investigated highlighting the high variability of the seismic performance of irregular structures.

The first procedure is based on the nonlinear static analyses reported in Section 3. The pushover curves, previously obtained, relative to the control points located at the height of $14.45 \mathrm{~m}$ (P5, P6, P7, P8 and P9) are combined considering the average value at each step of the analysis. They are used to perform the seismic assessment according to the N2 method [39] and the prescriptions reported in the EC8 $[29,30]$.

With this aim, the ultimate limit state (NC), associated to a global base shear reduction equal to $20 \%$ of the peak load, is considered. The equivalent single-degree-of-freedom (SDOF) system is defined by following the steps described in Section 4. The building is assimilated to a nonlinear single degree of freedom by dividing the base shear force $\left(V_{b}\right)$ and the displacement of the target point $(D)$ of a reference control point (in this case the average displacement at level $14.45 \mathrm{~m}$ ) by the modal participation factor $(\Gamma)$, according to the procedure described in [38].

In the space of the acceleration spectra $\left(S_{a}\right)$ and displacement spectra $\left(S_{d}\right)$, the coordinates of the SDOF system can be computed as $S_{d}=D / \Gamma$ and $S_{a}=V_{b} /\left(\Gamma m^{*} g\right)$, where $m^{*}$ is the mass associated to the SDOF system. Since the investigated directions involve not only the main directions, but also intermediate ones, and considering that it is not easy to identify the fundamental vibration modes along those directions from a modal analysis, here the fundamental mode shape along all the directions is approximately assessed consistently with the Italian code [38]; in particular, the mode shape in correspondence of the control points has been approximately estimated proportionally to the mass and height associated to each control point, thus inferring a unique modal participating factor for all 
the considered directions. From the simplified assumptions here adopted, the $\Gamma$ factor assumed in the vulnerability assessment has been estimated in 1.57, and the effective mass of the SDOF system has been assumed equal to $3650.9 \mathrm{t}$. Then, the bi-linear SDOF system is computed according to the procedure proposed in the Italian Code [38]. The main parameters of the equivalent SDOF systems, plotted in terms of acceleration and displacement format (A-D), are reported in Table 3, in which $T^{*}$ is the equivalent period, $S_{A y}$ and $S_{D y}$ are the spectral values associated to the elastic limit of pseudo-acceleration and displacement, respectively. The capacity ductility of the SDOF system turns out to be $\mu=S_{D u} / S_{D y}=D_{u} / D_{y}$.

Table 3. Assessment of the admissible peak ground acceleration (PGA).

\begin{tabular}{|c|c|c|c|c|c|c|c|c|c|}
\hline $\begin{array}{l}\text { Direction } \\
\left({ }^{\circ}\right)\end{array}$ & $\begin{array}{l}\text { Azimuth } \\
\left({ }^{\circ}\right)\end{array}$ & $\begin{array}{c}F^{*} y \\
(\mathbf{k N})\end{array}$ & $\begin{array}{c}k^{*} \\
(\mathrm{kN} / \mathrm{cm})\end{array}$ & $T^{*}(\mathrm{~s})$ & $S_{A y}(\mathrm{~g})$ & $S_{D y}(\mathrm{~cm})$ & $\mu_{u}(-)$ & $\begin{array}{c}\text { PGA } \\
\text { Capacity (g) }\end{array}$ & $\begin{array}{c}\text { PGA } \\
\text { Demand (g) }\end{array}$ \\
\hline 0 & 300 & 4559 & 10044 & 0.33 & 0.16 & 0.45 & 6.29 & 0.29 & 0.60 \\
\hline 60 & 240 & 6451 & 13360 & 0.29 & 0.23 & 0.48 & 4.20 & 0.24 & 0.60 \\
\hline 90 & 210 & 5975 & 12311 & 0.30 & 0.22 & 0.49 & 3.64 & 0.20 & 0.48 \\
\hline 120 & 180 & 7066 & 12878 & 0.29 & 0.25 & 0.55 & 4.28 & 0.27 & 0.55 \\
\hline 210 & 90 & 5471 & 14312 & 0.28 & 0.20 & 0.38 & 5.43 & 0.25 & 0.66 \\
\hline 240 & 60 & 6407 & 13364 & 0.29 & 0.23 & 0.48 & 1.54 & 0.09 & 0.60 \\
\hline 270 & 30 & 6041 & 17596 & 0.25 & 0.18 & 0.34 & 2.24 & 0.10 & 0.48 \\
\hline 300 & 0 & 6591 & 19184 & 0.24 & 0.24 & 0.34 & 2.14 & 0.10 & 0.55 \\
\hline 330 & 330 & 5751 & 10567 & 0.33 & 0.21 & 0.54 & 7.72 & 0.44 & 0.48 \\
\hline
\end{tabular}

Note: * makes reference to the equivalent bilinear SDOF system.

Considering the ductility demand equal to the ductility capacity of the system $\left(\mu=\mu_{u}\right)$, the reduction factor $\mathrm{R}(\mu)$, defined as the ratio between the elastic spectral acceleration demand and the maximum spectral acceleration of the nonlinear system $\left(S_{A y}\right)$, is computed by using the equal displacement rule $(\mathrm{R}=\mu)$. The PGA admissible for each limit state $\left(a_{g}\right)$ of the system is computed by equating the acceleration of the system $S_{A y}$ and the inelastic spectra acceleration $S_{A}\left(a_{g}, T^{*}, R\right)$, both associated to the fundamental period of the system. Figure 20 shows a schematic layout of how the procedure for the assessment of the PGA capacity works.

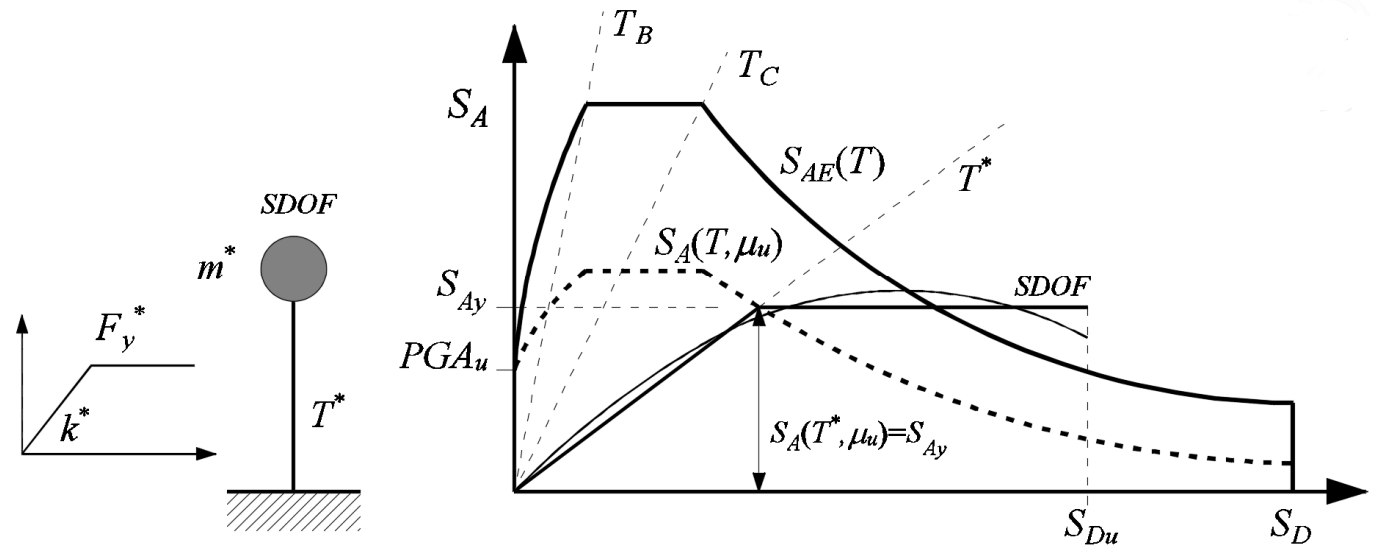

Figure 20. Procedure for the assessment of the admissible PGA.

In the same Table 3, in view of the actual orientation of the building, for each direction with respect to the principal axes of the building, the corresponding azimuth is reported. The accelerometric signal along a specific direction is obtained by composing the ground motion components of the ground motion occurred in L'Aquila on 6 April 2009 along the considered direction; then, the corresponding 
PGA is computed, as reported in the last column of Table 3. It is worth noting that the actual direction of the seismic input here considered hit the building in direction $300^{\circ}$ with respect to its main axes.

Figure 21 shows the admissible PGA at the Near Collapse limit state for each direction of the seismic action; the weakest directions of the building range from $240^{\circ}$ to $300^{\circ}$ with respect to the principal axes of the building. Besides, in Figure 23, the ratio between capacity and demand in terms of PGA is reported with the dashed line. The safety factor is lower than one for all the considered directions and ranges between 0.145 and 0.919 . The safety factor, in this case, represents the ratio between the capacity of the structure in terms of PGA (or ductility as shown later) and the corresponding demand associated to the actual seismic input occurred during the main shock of L'Aquila earthquake.

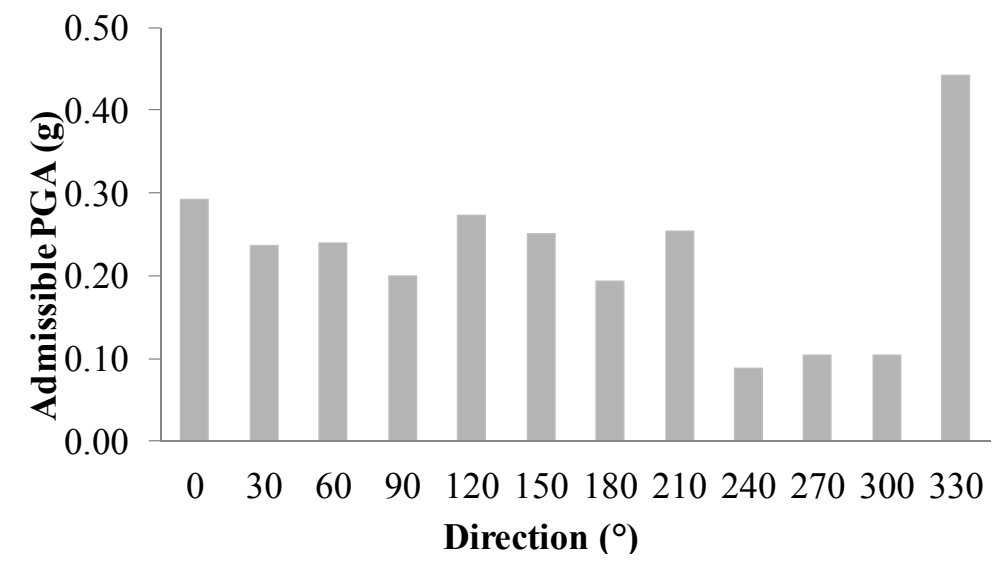

Figure 21. Assessment of the admissible PGA along all the investigated directions.

The second procedure for the assessment of the seismic performance of the building is based on the nonlinear dynamic analyses on the SDOF systems reported in Table 3 (one for each of the considered directions). An elastic-perfectly plastic constitutive scheme was adopted considering the unloading stiffness equal to the initial stiffness. The input was evaluated combining the components of the ground motion occurred in L'Aquila on 6 April 2009 along the considered directions and the ductility demand was assessed as the ratio between the maximum displacement obtained by the nonlinear dynamic analyses conducted on the SDOF systems and the yielding displacement of the bilinear curve. In Table 4 , the ductility demand $\mu_{d}$ observed by the numerical simulations is compared with the ductility capacity $\mu_{u}$ associated to the pushover curves, already given in Table 3 .

Table 4. Assessment of the ductility capacity.

\begin{tabular}{ccc}
\hline $\begin{array}{c}\text { Direction } \\
\mathbf{(}^{\circ}\end{array}$ & $\begin{array}{c}\text { Azimuth } \\
\left({ }^{\circ}\right)\end{array}$ & $\boldsymbol{\mu}_{\boldsymbol{d}}(\boldsymbol{-})$ \\
\hline 0 & 300 & 13.97 \\
30 & 270 & 16.83 \\
60 & 240 & 7.89 \\
90 & 210 & 11.06 \\
120 & 180 & 5.60 \\
150 & 150 & 9.69 \\
180 & 120 & 14.86 \\
210 & 90 & 17.63 \\
240 & 60 & 7.97 \\
270 & 30 & 13.57 \\
300 & 0 & 10.86 \\
330 & 330 & 8.23 \\
\hline
\end{tabular}


Figure 22 shows the admissible ductility demand inferred by the nonlinear dynamic analyses for each direction of the seismic action; the weakest directions of the building correspond to $120^{\circ}$ and $240^{\circ}$ with respect to the principal axes of the building. Besides, in Figure 23, the ratio between capacity and demand in terms of ductility is reported with the continuous line. The safety factor is lower than one for all the considered directions and ranges between 0.165 and 0.938 .

The two considered procedures seem to lead to very similar results, as shown in the comparison reported in Figure 23, for all considered directions and exhibit a high variability of the safety factor with the direction of the seismic input. In both cases, the safety factors are lower than the unit value, which indicates the safety of the structure with respect to the achievement of the Near Collapse Limit State, with reference to the actual seismic event to which the building was subjected. This results is in contrast with the evidence that the building actually did not reach that Limit State during the event. The latter aspect might be justified by the adopted mechanical properties which were estimated without a proper in-situ investigation campaign and considering a further penalty factor with respect to the mechanical properties suggested by the Italian code [38]. However, the proposed approach led to a conservative estimation of the capacity of the building. Further improvements in the simplified vulnerability assessment procedure could involve an improved definition of the SDOF system, which is defined just like for isolated buildings, although, in this case, it would be more appropriate to see the structure as an assemblage of several structural units interacting with each other.

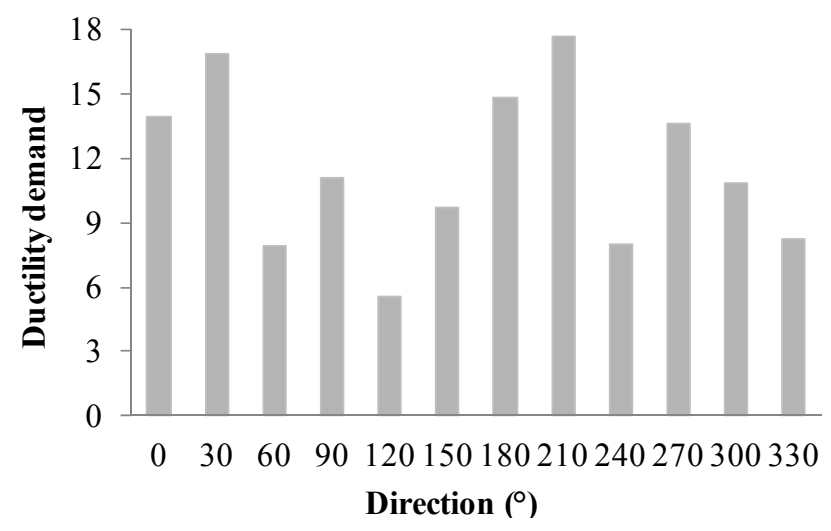

Figure 22. Assessment of the admissible ductility along all the investigated directions.

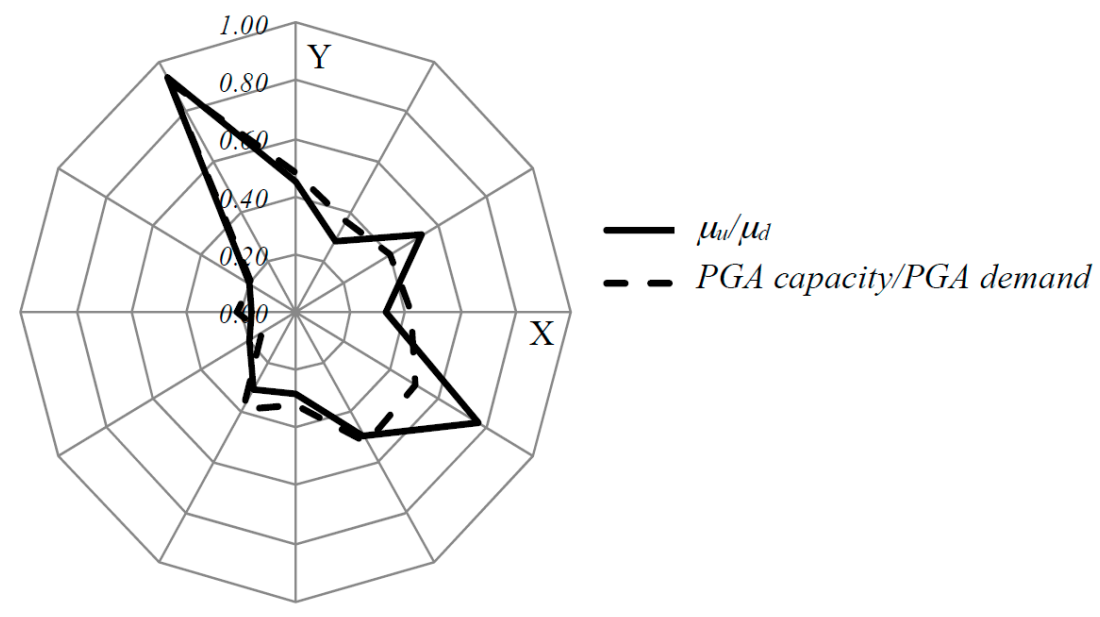

Figure 23. Comparison between the two proposed seismic vulnerability procedures all the investigated directions: ratio between capacity and demand in terms of ductility and peak ground acceleration (PGA). 


\section{Conclusions}

In this paper, the seismic vulnerability of an ancient palace located in L'Aquila (Italy) and subjected to the earthquake occurred in 2009 is investigated. A historical survey of the building, oriented to the reconstruction of the past strengthening interventions, was made. A complete structural assessment of the palace was performed, considering a global model to investigate the overall response and a local model of one of the noble hall, in which the frescoed surmounting vault partially collapsed. The two numerical models were implemented, aiming at grasping both the global seismic response of the building and assessing the so-called "secondary elements". The models were implemented making use of a discrete element approach recently introduced by some of the authors; in particular, the global model was analysed by considering a plane model, since the building globally showed a box behaviour, whereas the hall was investigated with a more sophisticated three-dimensional discrete macro-element, able to model curved elements as well. The assumptions made in the numerical models descend on a critical study of the available documents which date back to the structural retrofit made in the 1990s. The performed numerical analyses allowed justifying the crack pattern of the building observed in the field and the partial collapse of the mirror vault in the noble hall. In addition, an investigation on the global model was performed by varying the load direction; an original comprehensive representation of the pushover curves is proposed. Finally, a global vulnerability assessment of the building was performed in terms of PGA and ductility; in the first case the results were compared with the Peak Ground Acceleration associated to the main seismic event occurred in L'Aquila in 2009, in the second case the ductility demand of an equivalent SDOF system was compared with the capacity obtained by the pushover curves. The proposed procedures are in good agreement and allowed identifying the weakest directions for the building.

Acknowledgments: The authors thank Giuseppe Margani and Rosa Caponnetto for coordinating the detailed relief activity and the graphical rendering reported in [18], which allowed the present accurate structural modelling of Palazzo Gualtieri, and are grateful to Vittorio Polidori and Ugo Lepidi for their valuable collaboration in reconstructing and sharing many technical aspects of the past strengthening interventions of structural retrofitting on Palazzo Gualtieri.

Author Contributions: All the authors conceived the idea, developed the content of the paper, wrote the paper and revised it.

Conflicts of Interest: The authors declare no conflict of interest.

\section{References}

1. Chioccarelli, E.; Iervolino, I. Near-source seismic demand and pulse-like records: A discussion for L'Aquila earthquake. Earthq. Eng. Struct. Dyn. 2010, 39, 1039-1062. [CrossRef]

2. Indirli, M.; Kouris, L.A.S.; Formisano, A.; Borg, R.P.; Mazzolani, F.M. Seismic damage assessment of unreinforced masonry structures after the Abruzzo 2009 earthquake: The case study of the historical centers of L'Aquila and Castelvecchio Subequo. Int. J. Archit. Herit. 2013, 7, 536-578. [CrossRef]

3. Carocci, C.F. Small centres damaged by 2009 L'Aquila earthquake: On site analyses of historical masonry aggregates. Bull. Earthq. Eng. 2012, 10, 45-71. [CrossRef]

4. Santucci de Magistris, F.; D’onofrio, A.; Evangelista, L.; Foti, S.; Maraschini, M.; Monaco, P.; Amoroso, S.; Totani, G.; Lanzo, G.; Pagliaroli, A.; et al. Geotechnical characterization of the Aterno Valley for site response analysis. Riv. Ital. Geotec. 2013, 47, 23-43.

5. Brandonisio, G.; Lucibello, G.; Mele, E.; Luca, A.D. Damage and performance evaluation of masonry churches in the 2009 L'Aquila earthquake. Eng. Fail. Anal. 2013, 34, 693-714. [CrossRef]

6. Lagomarsino, S. Damage assessment of churches after L'Aquila earthquake (2009). Bull. Earthq. Eng. 2012, 10, 73-92. [CrossRef]

7. Boscato, G.; Pizzolato, M.; Russo, S.; Tralli, A. Seismic behavior of a complex historical church in L'Aquila. Int. J. Archit. Herit. 2014, 8, 718-757. [CrossRef]

8. Gattulli, V.; Antonacci, E.; Vestroni, F. Field observations and failure analysis of the Basilica S. Maria di Collemaggio after the 2009 L'Aquila earthquake. Eng. Fail. Anal. 2013, 34, 715-734. [CrossRef] 
9. Pantò, B.; Cannizzaro, F.; Caddemi, S.; Caliò, I. 3D macro-element modelling approach for seismic assessment of historical masonry churches. Adv. Eng. Softw. 2016, 97, 40-59. [CrossRef]

10. Cimellaro, G.P.; Piantà, S.; De Stefano, A. Output-only modal identification of ancient L'Aquila city hall and civic tower. J. Struct. Eng. 2012, 138, 481-491. [CrossRef]

11. Ceci, A.M.; Contento, A.; Fanale, L.; Galeota, D.; Gattulli, V.; Lepidi, M.; Potenza, F. Structural performance of the historic and modern buildings of the University of L'Aquila during the seismic events of April 2009. Eng. Struct. 2010, 32, 1899-1924. [CrossRef]

12. Cardoso, R.; Lopes, M.; Bento, R. Seismic evaluation of old masonry buildings. Part I: Method description and application to a case-study. Eng. Struct. 2005, 27, 2024-2035. [CrossRef]

13. Mallardo, V.; Malvezzi, R.; Milani, E.; Milani, G. Seismic vulnerability of historical masonry buildings: A case study in Ferrara. Eng. Struct. 2008, 30, 2223-2241. [CrossRef]

14. Betti, M.; Bartoli, G.; Orlando, M. Evaluation study on structural fault of a Renaissance Italian palace. Eng. Struct. 2010, 32, 1801-1813. [CrossRef]

15. Castellazzi, G.; D'Altri, A.M.; De Miranda, S.; Ubertini, S. An innovative numerical modeling strategy for the structural analysis of historical monumental buildings. Eng. Struct. 2017, 132, 229-248. [CrossRef]

16. Castori, G.; Borri, A.; De Maria, A.; Corradi, M.; Sisti, R. Seismic vulnerability assessment of a monumental masonry building. Eng. Struct. 2017, 136, 454-465. [CrossRef]

17. Andreini, M.; De Falco, A.; Giresini, L.; Sassu, M. Structural analysis and consolidation strategy of the historic Mediceo Aqueduct in Pisa (Italy). Appl. Mech. Mater. 2013, 351-352, 1354-1357. [CrossRef]

18. Caliò, I.; Cannizzaro, F.; Marletta, M.; Intelisano, M.; Pantò, B.; Caponetto, R.; Margani, G.; Lepidi, M. L'università e la Ricerca per l'Abruzzo: Il Patrimonio Culturale Dopo il Terremoto del 6 Aprile 2009 (In Italian); Milano, L., Morisi, C., Calderini, C., Donatelli, A., Eds.; TEXTUS EDIZIONI: L'Aquila, Italy, 2009.

19. Caliò, I.; Marletta, M.; Pantò, B. A new discrete element model for the evaluation of the seismic behaviour of unreinforced masonry buildings. Eng. Struct. 2012, 40, 327-338. [CrossRef]

20. Caliò, I.; Pantò, B. A macro-element modelling approach of Infilled Frame Structures. Comput. Struct. 2014, 143, 91-107. [CrossRef]

21. Caliò, I.; Cannizzaro, F.; D’Amore, E.; Marletta, M.; Pantò, B. A new discrete-element approach for the assessment of the seismic resistance of composite reinforced concrete-masonry buildings. In Proceedings of the Seismic Engineering International Conference Commemorating the 1908 Messina and Reggio Calabria Earthquake, Reggio Calabria, Italy, 8-11 July 2008; Volume 1020, pp. 832-839.

22. Caddemi, S.; Caliò, I.; Cannizzaro, F.; Pantò, B. A new computational strategy for the seismic assessment of infilled frame structures. In Proceedings of the 2013 Civil-Comp, Sardinia, Italy, 3-6 September 2013.

23. Marques, R.; Lourenço, P.B. Possibilities and comparison of structural component models for the seismic assessment of modern unreinforced masonry buildings. Comput. Struct. 2011, 89, 2079-2091. [CrossRef]

24. Bartoli, G.; Betti, M.; Biagini, P.; Borghini, A. Epistemic Uncertainties in Structural Modeling: A Blind Benchmark for Seismic Assessment of Slender Masonry Towers. J. Perform. Constr. Facil. 2017, 31, 04017067. [CrossRef]

25. Pantò, B.; Cannizzaro, F.; Caliò, I.; Lourenço, P.B. Numerical and experimental validation of a 3D macro-model for the in-plane and out-of-plane behaviour of unreinforced masonry walls. Int. J. Archit. Herit. 2017, 11, 1-19.

26. Cannizzaro, F.; Lourenço, P.B. Simulation of Shake Table Tests on Out-of-Plane Masonry Buildings. Part (VI): Discrete Element Approach. Int. J. Archit. Herit. 2017, 11, 125-142. [CrossRef]

27. Caliò, I.; Cannizzaro, F.; Marletta, M. A discrete element for modeling masonry vaults. Adv. Mater. Res. 2010, 133-134, 447-452. [CrossRef]

28. Caddemi, S.; Caliò, I.; Cannizzaro, F.; Pantò, B. The Seismic Assessment of Historical Masonry Structures. In Proceedings of the 12th International Conference on Computational Structures Technology, Naples, Italy, 2-5 September 2014.

29. European Committee for Standardization. EN 1998-3: 2005 Part 3 of the Eurocode 8-Design of Structures for Earthquake Resistance. Section 2: Performance Requirements and Compliance Criteria. Sub-Section 2.2: Compliance Criteria; European Committee for Standardization: Brussels, Belgium, 2005.

30. European Committee for Standardization. EN 1998-3: 2005 Eurocode 8: Design of Structures for Earthquake Resistance, Part 3: Assessment and Retrofitting of Buildings; European Committee for Standardization: Brussels, Belgium, 2005. 
31. Pantò, B.; Caliò, I.; Lourenço, P.B. Seismic safety evaluation of reinforced concrete masonry infilled frames using macro modelling approach. Bull. Earthq. Eng. 2017, 15, 3871-3895. [CrossRef]

32. Dander, M.; Moretti, M. Architettura Civile Aquilana—Dal XIV al XIX Secolo; L.U. Japadre 735 Editore: L'Aquila, Italy, 1974. (In Italian)

33. Decreto Ministeriale 20/11/1987: Norme tecniche per la progettazione, esecuzione e collaudo degli edifici in muratura e per il loro consolidamento. Available online: http:/ / www.dist.unina.it/doc/norme/04/04\% 2020-11-87.pdf (accessed on 1 September 2017). (In Italian)

34. Casapulla, C.; Portioli, F. Experimental tests on the limit states of dry-jointed tuff blocks. Mater. Struct. 2016, 49, 751-767. [CrossRef]

35. Casapulla, C.; Maione, A. Formulating the Torsion Strength of Dry-Stacked Stone Blocks by Comparing Convex and Concave Contact Formulations and Experimental Results. Indian J. Sci. Technol. 2016, 9, 1-7. [CrossRef]

36. Casapulla, C.; Argiento, L.U. The comparative role of friction in local out-of-plane mechanisms of masonry buildings. Pushover analysis and experimental investigation. Eng. Struct. 2016, 126, 158-173. [CrossRef]

37. Caddemi, S.; Caliò, I.; Cannizzaro, F.; Occhipinti, G.; Pantò, B. A parsimonious discrete model for the seismic assessment of monumental structures. In Proceedings of the 2015 Fifteenth International Conference on Civil, Structural and Environmental Engineering Computing, Prague, Czech, 1-4 September 2015.

38. NTC (2008): Approvazione delle nuove norme tecniche per le costruzioni, Gazzetta Ufficiale della Repubblica Italiana, n. 29 del 4 febbraio 2008-Suppl. Ordinario n. 30. Available online: http:/ / www.cslp.it/cslp/index. php?option=com_docman\&task=doc_download\&gid=3269\&Itemid=10 (accessed on 1 September 2017). (In Italian)

39. Fajfar, P.; Gašperšič, P. The N2 method for the seismic damage analysis of RC buildings. Earthq. Eng. Struct. Dyn. 1996, 25, 31-46. [CrossRef]

(C) 2017 by the authors. Licensee MDPI, Basel, Switzerland. This article is an open access article distributed under the terms and conditions of the Creative Commons Attribution (CC BY) license (http://creativecommons.org/licenses/by/4.0/). 